\title{
The ALMA-PILS survey: the first detection of doubly deuterated methyl formate $\left(\mathrm{CHD}_{2} \mathrm{OCHO}\right)$ in the ISM
}

\author{
S. Manigand ${ }^{1}$, H. Calcutt ${ }^{1}$, J. K. Jørgensen ${ }^{1}$, V. Taquet ${ }^{2}$, H. S. P. Müller ${ }^{3}$, A. Coutens ${ }^{4}$, S. F. Wampfler ${ }^{5}$, \\ N. F. W. Ligterink ${ }^{5}$, M. N. Drozdovskaya ${ }^{5}$, L. E. Kristensen ${ }^{1}$, M. H. D. van der Wiel ${ }^{6}$, and T. L. Bourke \\ ${ }^{1}$ Centre for Star and Planet Formation, Niels Bohr Institute \& Natural History Museum of Denmark, University of Copenhagen, \\ Øster Voldgade 5-7, 1350 Copenhagen K., Denmark \\ e-mail: sebastien@nbi.ku.dk \\ 2 INAF, Osservatorio Astrofisico di Arcetri, Largo E. Fermi 5, 50125 Firenze, Italy \\ ${ }^{3}$ I. Physikalisches Institut, Universität zu Köln, Zülpicher Str. 77, 50937 Köln, Germany \\ ${ }^{4}$ Laboratoire d'Astrophysique de Bordeaux, University of Bordeaux, CNRS, B18N, allé Geoffroy Saint-Hilaire, 33615 Pessac, \\ France \\ ${ }^{5}$ Center for Space and Habitability (CSH), University of Bern, Sidlestrasse 5, 3012 Bern, Switzerland \\ ${ }^{6}$ ASTRON Netherlands Institute for Radio Astronomy, PO Box 2, 7990 AA Dwingeloo, The Netherlands \\ ${ }^{7}$ SKA Organisation, Jodrell Bank Observatory, Lower Withington, Macclesfield, Cheshire SK11 9DL, UK
}

Received 16 February 2018 / Accepted 20 November 2018

\begin{abstract}
Studies of deuterated isotopologues of complex organic molecules can provide important constraints on their origin in star formation regions. In particular, the abundances of deuterated species are very sensitive to the physical conditions in the environment where they form. Because the temperatures in star formation regions are low, these isotopologues are enhanced to significant levels, which enables the detection of multiply deuterated species. However, for complex organic species, so far only the multiply deuterated variants of methanol and methyl cyanide have been reported. The aim of this paper is to initiate the characterisation of multiply deuterated variants of complex organic species with the first detection of doubly deuterated methyl formate, $\mathrm{CHD}_{2} \mathrm{OCHO}$. We use ALMA observations from the Protostellar Interferometric Line Survey (PILS) of the protostellar binary IRAS 16293-2422 in the spectral range of 329.1 GHz to $362.9 \mathrm{GHz}$. Spectra towards each of the two protostars are extracted and analysed using a local thermal equilibrium model in order to derive the abundances of methyl formate and its deuterated variants. We report the first detection of doubly deuterated methyl formate $\mathrm{CHD}_{2} \mathrm{OCHO}$ in the ISM. The $\mathrm{D}-$ to- $\mathrm{H}$ ratio $\left(\mathrm{D} / \mathrm{H}\right.$ ratio) of $\mathrm{CHD}_{2} \mathrm{OCHO}$ is found to be $2-3$ times higher than the $\mathrm{D} / \mathrm{H}$ ratio of $\mathrm{CH}_{2} \mathrm{DOCHO}$ for both sources, similar to the results for formaldehyde from the same dataset. The observations are compared to a gas-grain chemical network coupled to a dynamical physical model, tracing the evolution of a molecular cloud until the end of the Class 0 protostellar stage. The overall $\mathrm{D} / \mathrm{H}$ ratio enhancements found in the observations are of about the same magnitude as the predictions from the model for the early stages of Class 0 protostars. However, that the $\mathrm{D} / \mathrm{H}$ ratio of $\mathrm{CHD}_{2} \mathrm{OCHO}$ is higher than that of $\mathrm{CH}_{2} \mathrm{DOCHO}$ is still not predicted by the model. This suggests that a mechanism enhances the $\mathrm{D} / \mathrm{H}$ ratio of singly and doubly deuterated methyl formate that is not in the model, for instance, mechanisms for H-D substitutions. This new detection provides an important constraint on the formation routes of methyl formate and outlines a path forward in terms of using these ratios to determine the formation of organic molecules through observations of differently deuterated isotopologues towards embedded protostars.
\end{abstract}

Key words. astrochemistry - stars: formation - stars: protostars - ISM: molecules - ISM: individual objects: IRAS $16293-2422$

\section{Introduction}

The earliest stages of star formation are characterised by a rich and abundant molecular diversity in various environments. Complex organic molecules (COMs; molecules with six or more atoms that contain at least one carbon and hydrogen atom, Herbst \& van Dishoeck 2009) are particularly abundant in the gas phase close to the protostars, typically at $R<100 \mathrm{AU}$, where the dust temperature is high enough for the ice to sublimate. These inner warm regions around low-mass protostars, known as hot corinos (Ceccarelli 2004), also show enhanced D-to-H ratios (D/H ratio), or deuterium fractionation, with respect to the local galactic value of $2.0 \pm 0.1 \times 10^{-5}$ (Prodanović et al. 2010). These ratios are expected to be sensitive to the physical properties and evolutionary stage of the protostar and the chemical formation of specific species (Ceccarelli et al. 2014; Punanova et al. 2016). Therefore, inventories of their isotopic content may shed further light on the formation routes and the formation time of these important COMs.

The low-mass Class 0 protostellar binary IRAS 16293-2422 (IRAS 16293 hereafter) is considered one of the template sources for astrochemical studies. It is known to have a very rich spectrum with bright lines and abundant COMs (e.g. Blake et al. 1994; van Dishoeck et al. 1995; Cazaux et al. 2003; Caux et al. 2011; Jørgensen et al. 2012). IRAS 16293 is located in the nearby Ophiuchus molecular cloud complex at a distance of $141 \mathrm{pc}$ (Dzib et al. 2018) and is composed of two protostars A and B that are separated by $5{ }^{\prime \prime} 1$ (720 AU). The two components of the binary show quite different morphologies: the comparatively more luminous south-eastern source (IRAS 16293A, hereafter source A) shows an edge-on disc-like morphology, with an elongated dust continuum emission and a velocity gradient of $\sim 6 \mathrm{~km} \mathrm{~s}^{-1}$. In contrast, the north-western source (IRAS 16293B, hereafter source B) shows roughly circular dust continuum 
emission and narrow lines $\left(F W H M \approx 1 \mathrm{~km} \mathrm{~s}^{-1}\right)$, a factor of three narrower than IRAS 16293 A (i.e. $F W H M \approx 2.5 \mathrm{~km} \mathrm{~s}^{-1}$ ), which indicates a more face-on morphology.

This study is focused on deuterated COMs and uses data from the Protostellar Interferometric Line Survey (PILS; Jørgensen et al. 2016), an ALMA survey of IRAS 16293. Previous single-dish studies of IRAS 16293 have shown high $\mathrm{D} / \mathrm{H}$ ratio for relatively small molecules such as methanol $\left(\mathrm{CH}_{3} \mathrm{OH}\right)$ and formaldehyde $\left(\mathrm{H}_{2} \mathrm{CO}\right)$, although these values have high uncertainties because the single-dish observations are unresolved (Loinard et al. 2000; Parise et al. 2002). The high angular resolution and sensitivity measurements from PILS opens up a more detailed analysis of the $\mathrm{D} / \mathrm{H}$ ratio for different species. The PILS data for IRAS 16293B have been used for example to demonstrate that the $\mathrm{D} / \mathrm{H}$ ratio for $\mathrm{HDCO}$ and $\mathrm{D}_{2} \mathrm{CO}$ differs (3.2\% and $9.1 \%$, respectively; Persson et al. 2018) and also provided measurements of mono-deuterated larger $\mathrm{COMs}$, for instance molecules formed from $\mathrm{CH}_{3} \mathrm{O}$ or $\mathrm{HCO}$ radicals, such as methyl formate, glycolaldehyde $\left(\mathrm{CH}_{2} \mathrm{OHCHO}\right)$, ethanol $\left(\mathrm{C}_{2} \mathrm{H}_{5} \mathrm{OH}\right)$, and dimethyl ether $\left(\mathrm{CH}_{3} \mathrm{OCH}_{3}\right)$, reported with a $\mathrm{D} / \mathrm{H}$ ratio of $4-8 \%$ (Jørgensen et al. 2018) and formamide $\left(\mathrm{NH}_{2} \mathrm{CHO}\right)$, with a $\mathrm{D} / \mathrm{H}$ ratio of $\approx 2 \%$ (Coutens et al. 2016). The high sensitivity of the dataset enables a search to be undertaken for multiply deuterated variants of these more complex COMs and to investigate whether similar differences are present in the deuteration levels between the mono- and multiply deuterated variants as an imprint of their formation.

In this paper, we report the first detection of a doubly deuterated isotopologue of methyl formate $\left(\mathrm{CHD}_{2} \mathrm{OCHO}\right)$ in the interstellar medium (ISM) towards both components of the IRAS 16293 protostellar binary. In addition, the other methyl formate deuterated isotopologues are identified towards the two protostars of the binary system, and we compare the derived $\mathrm{D} / \mathrm{H}$ ratio with predictions based on ice grain chemistry.

\section{Observations and spectroscopic data}

The ALMA observations cover a frequency range of $329.1 \mathrm{GHz}$ to $362.9 \mathrm{GHz}$, with a spectral resolution of $0.2 \mathrm{~km} \mathrm{~s}^{-1}$, or $0.244 \mathrm{MHz}$, and a restoring beam of 0.5 . The data reach a sensitivity of $\sim 5-7 \mathrm{mJy}^{-1} \mathrm{bm}^{-1} \mathrm{~km} \mathrm{~s}^{-1}$ across the entire frequency range, increasing the sensitivity by one to two orders of magnitude compared to previous surveys. The phase centre is located between the two continuum sources at $\alpha_{\mathrm{J} 2000}=16^{\mathrm{h}} 32^{\mathrm{m}} 22^{\mathrm{s}} .72$ and $\delta_{\mathrm{J} 2000}=-24^{\circ} 28^{\prime} 34^{\prime \prime} 3$. Further details of the data reduction and continuum subtraction can be found in Jørgensen et al. (2016). Two positions, offset by 0.6 and 0.5 from the peak continuum positions, have been investigated towards IRAS 16293A and IRAS 16293B, respectively. The offset positions are the same as those used in previous PILS studies (Lykke et al. 2017; Ligterink et al. 2017; Calcutt et al. 2018b). The spectroscopic data used in this study are given in Appendix A.

\section{Results and analysis}

We searched for $\mathrm{CHD}_{2} \mathrm{OCHO}$ towards both sources, and for $\mathrm{CH}_{2} \mathrm{DOCHO}, \mathrm{CH}_{3} \mathrm{OCDO}$ and $\mathrm{CH}_{3} \mathrm{OCHO}$ towards source $\mathrm{A}$; Jørgensen et al. (2018) reported on the last three isotopologues towards source B. To identify the presence of the species in the gas, a Gaussian line profile synthetic spectrum was used and compared to extracted spectra towards both sources of the binary system. Given the high density of the gas at the scales of the PILS data, the gas of the inner region is assumed to be in local thermodynamic equilibrium (LTE, see Jørgensen et al. 2016).
Fifty four lines of $\mathrm{CHD}_{2} \mathrm{OCHO}$ were identified above $3 \sigma$, including 18 that are unblended with other species towards source $\mathrm{B}$, and 5 lines above $3 \sigma$, including 2 unblended lines towards source A. In addition, 419, 82, and 3 unblended lines above the $3 \sigma$ detection threshold were identified for $\mathrm{CH}_{3} \mathrm{OCHO}, \mathrm{CH}_{2} \mathrm{DOCHO}$, and $\mathrm{CH}_{3} \mathrm{OCDO}$, respectively, towards IRAS 16293A. A significant number of lines of the main isotopologue (i.e. 260 lines) were found to be optically thick and were excluded in the subsequent fits.

A large $\chi^{2}$ grid of spectral models was run in order to constrain the excitation temperature, $T_{\text {ex }}$, the column density, $N_{\text {tot }}$, the peak velocity, $V_{\text {peak }}$, and the line full width at half-maximum, FWHM, that best reproduce the extracted spectra. The grid covered column density values from $1 \times 10^{15}$ to $1 \times 10^{18} \mathrm{~cm}^{-2}$ and excitation temperatures from 100 to $300 \mathrm{~K}$. Ranges of $2.0-2.6 \mathrm{~km} \mathrm{~s}^{-1}$ and $0.6-1.0 \mathrm{~km} \mathrm{~s}^{-1}$ for FWHM and $V_{\text {peak }}$, respectively, were used for source $\mathrm{A}$. The ranges for source $\mathrm{B}$ were $0.8-1.2 \mathrm{~km} \mathrm{~s}^{-1}$ and $2.5-2.9 \mathrm{~km} \mathrm{~s}^{-1}$ for FWHM and $V_{\text {peak }}$, respectively. For source A, the FWHM and the peak velocity are $2.4 \pm 0.2 \mathrm{~km} \mathrm{~s}^{-1}$ and $0.8 \pm 0.2 \mathrm{~km} \mathrm{~s}^{-1}$, respectively, which is in good agreement with the one found for the N-bearing molecules, $F W H M=2.2$ and $2.5 \mathrm{~km} \mathrm{~s}^{-1}$ and $V_{\text {peak }}=0.8$ and $0.8 \mathrm{~km} \mathrm{~s}^{-1}$ from Calcutt et al. (2018b) and Ligterink et al. (2017), respectively. The FWHM and the peak velocity are found to be $1.0 \pm 0.2 \mathrm{~km} \mathrm{~s}^{-1}$ and $2.7 \pm 0.2 \mathrm{~km} \mathrm{~s}^{-1}$, respectively, for the B source, similar to previous studies on the same dataset (e.g. Coutens et al. 2016; Lykke et al. 2017; Drozdovskaya et al. 2018). Each line was weighted with the spectral resolution and a factor corresponding to the risk of blending effect with other species. In all models, the same source size $\theta_{\mathrm{s}}=0.5$ was adopted. This value corresponds to the deconvolved extent of the marginally resolved sources in the beam of these ALMA observations (Jørgensen et al. 2016). This source size was also adopted in all previous studies using the PILS dataset. A reference spectrum based on the column density of the detected species in previous publications on the same dataset was used to reduce blending effects that are due to the larger line widths towards IRAS $16293 \mathrm{~A}$ and the high line concentration in the spectra.

The best fit for the excitation temperature is $115 \pm 25 \mathrm{~K}$ for $\mathrm{CH}_{3} \mathrm{OCHO}$ towards the offset position of IRAS 16293A. This value is significantly different from the excitation temperature found towards IRAS 16293B for the same molecules (i.e. $300 \mathrm{~K}$, Jørgensen et al. 2018). The low dispersion in the upper-state energy values, $E_{\mathrm{u}}$, of the most intense and unblended $\mathrm{CHD}_{2} \mathrm{OCHO}$ lines, between 260 and $320 \mathrm{~K}$, means that the excitation temperature cannot be constrained properly. Therefore, we used the same excitation temperature as for the main species towards both sources, respectively. We failed to find any anti-coincidences between the synthetic and observed spectrum, which suggests that these excitation temperatures provide a good fit. Unless the excitation temperatures differ between the various isotopologues, their derived relative abundances do not significantly depend on the exact excitation temperature considered.

Figure 1 shows the brightest $\mathrm{CHD}_{2} \mathrm{OCHO}$ lines towards the two sources. In general, the fit is better towards source B than towards source A because of the narrower line widths, which reduce the confusion that is due to line blending. More fitted lines of $\mathrm{CH}_{3} \mathrm{OCHO}, \mathrm{CH}_{2} \mathrm{DOCHO}, \mathrm{CH}_{3} \mathrm{OCDO}$, and $\mathrm{CHD}_{2} \mathrm{OCHO}$ are shown in Figs. D.1, D.2, and E.1.

Table 1 shows the derived column densities of $\mathrm{CH}_{3} \mathrm{OCHO}$, $\mathrm{CH}_{2} \mathrm{DOCHO}, \mathrm{CH}_{3} \mathrm{OCDO}$, and $\mathrm{CHD}_{2} \mathrm{OCHO}$ towards IRAS $16293 \mathrm{~A}$ and $\mathrm{B}$. In order to take the continuum contribution to the line emission as a background temperature into account, 


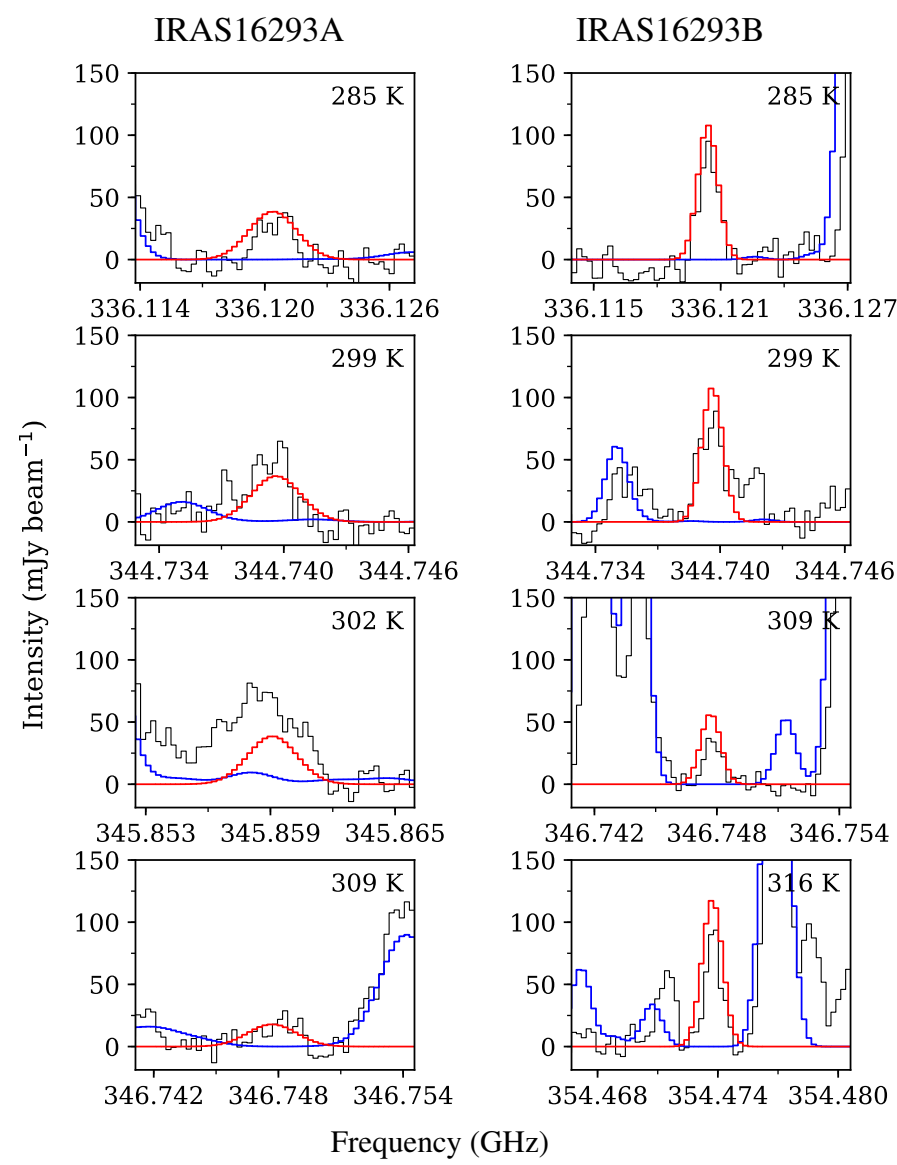

Fig. 1. Selection of the brightest $\mathrm{CHD}_{2} \mathrm{OCHO}$ transitions towards IRAS 16293A (left panels) and IRAS 16293B (right panels). The synthetic spectra are over-plotted in red, a reference spectrum is plotted in blue, and the data are shown in black. The upper-level energies are indicated in the top right corner of each plot.

Table 1. Derived column densities of the methyl formate isotopologues towards offset positions (see Sect. 3).

\begin{tabular}{lcc}
\hline \hline & \multicolumn{2}{c}{$N_{\text {tot }}\left(\mathrm{cm}^{-2}\right)$} \\
\cline { 2 - 3 } Species & IRAS 16293A & IRAS 16293B \\
\hline $\mathrm{CHD}_{2} \mathrm{OCHO}$ & $5.3 \pm 1.6 \times 10^{15}$ & $1.1 \pm 0.2 \times 10^{16}$ \\
$\mathrm{CH}_{2}$ DOCHO & $2.3 \pm 0.7 \times 10^{16}$ & $4.8 \pm 0.5 \times 10^{16 a}$ \\
$\mathrm{CH}_{3} \mathrm{OCDO}$ & $4.5 \pm 1.3 \times 10^{15}$ & $1.5 \pm 0.2 \times 10^{16 a}$ \\
$\mathrm{CH}_{3} \mathrm{OCHO}$ & $2.7 \pm 0.8 \times 10^{17}$ & $2.6 \pm 0.3 \times 10^{17 a}$ \\
\hline
\end{tabular}

References. ${ }^{(a)}$ Jørgensen et al. (2018).

a correction factor was determined to correct for the derived column density, based on the excitation temperature and the continuum flux (see Calcutt et al. 2018a). At the 0.' 6 offset position towards source A, the continuum flux is $0.55 \mathrm{Jy}^{\text {beam }}{ }^{-1}$, corresponding to a brightness temperature of $30 \mathrm{~K}$ and a correction factor of 1.27 at $115 \mathrm{~K}$. The continuum correction factor at $300 \mathrm{~K}$ for the $0 . .5$ offset position towards source B was 1.05 (Jørgensen et al. 2016).

The spatial extent of the molecular emission towards IRAS 16293A is particularly difficult to explore because of its geometry, which is different to that of source B. The $6 \mathrm{~km} \mathrm{~s}^{-1}$ velocity gradient in the NE-SW axis (Pineda et al. 2012; Favre et al. 2014b) and the high concentration of lines make standard integrated emission maps almost impossible without contamination by other molecular lines. Calcutt et al. (2018b) developed a new method for analysing the spatial emission of such velocity structures, called velocity-corrected integrated emission maps (VINE maps hereafter). Instead of integrating the same channels over the map, they use the peak velocity at each pixel of a bright methanol line, the $J_{K}=7_{3} \rightarrow 6_{3}, v_{t}=1$ line of the E symmetrical conformer at $337.519 \mathrm{GHz}$, as a reference to shift the integration channel range. This methanol transition traces the velocity gradient of the source and hence is suitable to be used for the velocity correction (see Calcutt et al. 2018b, for more details on the method and the velocity map of the reference transition in Fig. 5 of their paper).

Figure 2 shows the VINE map of two unblended transitions of each deuterated isotopologue of methyl formate. The integration ranges are 3.2 and $1.2 \mathrm{~km} \mathrm{~s}^{-1}$ centred on the corrected peak velocity towards sources $\mathrm{A}$ and $\mathrm{B}$, respectively. Towards IRAS 16293B, the spatial distribution of methyl formate isotopologues traces the most compact region of the protostellar envelope, corresponding to the hot corino region. Towards source A, the distribution shows a doubly peaked structure along the velocity gradient NE-SW axis that could correspond to the previously reported continuum emission feature at $1 \mathrm{~cm}($ e.g. Wootten 1989; Chandler et al. 2005; Pech et al. 2010) and shown by the N-bearing species (Calcutt et al. 2018b). Further VINE maps of other transitions of $\mathrm{CH}_{3} \mathrm{OCHO}$ and their deuterated isotopologues are given in Figs. C.1-C.4.

\section{Astronomical implications}

This study presents the first detection of a doubly deuterated large complex organic molecule, that is, a molecule with a longer main chain than methanol. This makes it unique. Table 2 shows the $\mathrm{D} / \mathrm{H}$ ratio of $\mathrm{CH}_{2} \mathrm{DOCHO}$ and $\mathrm{CHD}_{2} \mathrm{OCHO}$ determined from the abundance ratios (see Appendix $\mathrm{B}$ ). Their $\mathrm{D} / \mathrm{H}$ ratios is higher than the local $\mathrm{D} / \mathrm{H}$ ratio of $2.0 \pm 0.1 \times 10^{-5}$ in the ISM (Prodanović et al. 2010), as observed for most of the organic molecules towards hot corinos (e.g. Parise et al. 2006). The $\mathrm{D} / \mathrm{H}$ ratio of $\mathrm{CHD}_{2} \mathrm{OCHO}$ is also higher towards both sources than the $\mathrm{D} / \mathrm{H}$ ratio of $\mathrm{CH}_{2} \mathrm{DOCHO}$. The enhanced $\mathrm{D} / \mathrm{H}$ ratio of the doubly deuterated isotopologue with respect to the singly deuterated $\mathrm{D} / \mathrm{H}$ ratio is also seen for formaldehyde towards source B (Persson et al. 2018).

To place these results into context, we compared the abundance to the predictions of the gas-grain chemical model of the earliest stages of hot core formation from Taquet et al. (2014). The model couples the astrochemical model GRAINOBLE (Taquet et al. 2012) with a 1D evolutionary core-collapse model. The physical model starts at the molecular cloud stage and then follows the static formation of the dense prestellar core. When the central density reaches $2 \times 10^{5} \mathrm{~cm}^{-3}$, the free-fall core collapse is triggered and the time defined as $t=0$. After one free-fall timescale $\left(\sim 9.4 \times 10^{4} \mathrm{yr}\right)$, a protostar is formed and heats up the protostellar envelope, while the envelope shells of increasing radii are gradually accreted at increasing times in an inside-out manner. The end of the Class 0 protostellar stage is defined as the point when the central protostar has accreted half of the total (envelope+protostellar) mass in the system. The kinetic temperature in the deeply embedded envelope during the prestellar phase is lower than $10 \mathrm{~K}$ and only increases after the protostar is formed. The temperature profile during this stage is computed using the 1D dust radiative transfer code DUSTY (Ivezic \& Elitzur 1997). 
Table 2. Abundance and D/H ratio of methyl formate and formaldehyde isotopologues observed towards IRAS 16293A and B and in the model used in the discussion.

\begin{tabular}{|c|c|c|c|c|}
\hline \multirow[b]{2}{*}{ Species } & \multicolumn{2}{|c|}{ IRAS 16293A } & \multicolumn{2}{|c|}{ IRAS 16293B } \\
\hline & $N_{\text {tot }}$ ratios $\left(\times 10^{-2}\right)$ & $\mathrm{D} / \mathrm{H}$ ratio $\left(\times 10^{-2}\right)$ & $N_{\text {tot }}$ ratios $\left(\times 10^{-2}\right)$ & D/H ratio $\left(\times 10^{-2}\right)$ \\
\hline $\mathrm{CH}_{2} \mathrm{DOCHO} / \mathrm{CH}_{3} \mathrm{OCHO}$ & $8.5 \pm 3.6$ & $2.8 \pm 0.4$ & $18 \pm 2.7^{a}$ & $6.1 \pm 0.3^{a}$ \\
\hline $\mathrm{CH}_{3} \mathrm{OCDO} / \mathrm{CH}_{3} \mathrm{OCHO}$ & $1.7 \pm 0.7$ & $1.7 \pm 0.7$ & $5.7 \pm 0.9^{a}$ & $5.7 \pm 0.9^{a}$ \\
\hline $\mathrm{CHD}_{2} \mathrm{OCHO} / \mathrm{CH}_{3} \mathrm{OCHO}$ & $2.0 \pm 0.8$ & $8.2 \pm 0.6$ & $4.2 \pm 0.6$ & $12.0 \pm 0.3$ \\
\hline $\mathrm{HDCO} / \mathrm{H}_{2} \mathrm{CO}$ & - & - & $6.8 \pm 1.2^{b}$ & $3.3 \pm 1.0^{b}$ \\
\hline \multirow[t]{2}{*}{$\mathrm{D}_{2} \mathrm{CO} / \mathrm{H}_{2} \mathrm{CO}$} & - & - & $0.9 \pm 0.2^{b}$ & $9.2 \pm 1.0^{b}$ \\
\hline & \multicolumn{2}{|c|}{ model $^{c}$ "early time" } & \multicolumn{2}{|c|}{ model c "late time" } \\
\hline Species & $N_{\text {tot }}$ ratios $\left(\times 10^{-2}\right)$ & $\mathrm{D} / \mathrm{H}$ ratio $\left(\times 10^{-2}\right)$ & $\overline{N_{\text {tot }} \text { ratios }\left(\times 10^{-2}\right)}$ & $\mathrm{D} / \mathrm{H}$ ratio $\left(\times 10^{-2}\right)$ \\
\hline$\overline{\mathrm{CH}_{2} \mathrm{DOCHO} / \mathrm{CH}_{3} \mathrm{OCHO}}$ & 21 & 7.0 & 0.65 & 0.22 \\
\hline $\mathrm{CH}_{3} \mathrm{OCDO} / \mathrm{CH}_{3} \mathrm{OCHO}$ & 9.2 & 9.2 & 0.0025 & 0.0025 \\
\hline $\mathrm{CHD}_{2} \mathrm{OCHO} / \mathrm{CH}_{3} \mathrm{OCHO}$ & $2.4^{d}$ & $8.9^{d}$ & $0.0016^{d}$ & $0.19^{d}$ \\
\hline $\mathrm{HDCO} / \mathrm{H}_{2} \mathrm{CO}$ & 4.1 & 2.1 & 0.42 & 0.21 \\
\hline $\mathrm{D}_{2} \mathrm{CO} / \mathrm{H}_{2} \mathrm{CO}$ & 0.18 & 2.4 & 0.00064 & 0.15 \\
\hline
\end{tabular}

References. ${ }^{(a)}$ Jørgensen et al. (2018); ${ }^{(b)}$ Persson et al. (2018); ${ }^{(c)}$ Taquet et al. (2014); ${ }^{(d)}$ V. Taquet, priv. comm.

The same chemical network is used during all the physical evolution steps of the system and combines gas phase and grain-surface chemistry. The gas-phase network uses the data from the KIDA database, as well as deuterated species and the spin states of $\mathrm{H}_{2}, \mathrm{H}_{2}^{+}$, and $\mathrm{H}_{3}^{+}$reactions. The grainsurface formalism to treat the chemical processes is based on the multi-layer approach developed by Hasegawa \& Herbst (1993). It includes the adsorption of gas-phase species, the diffusion on the surface, the reaction via the Langmuir-Hinshelwood mechanism, the thermal and chemical desorption, cosmic-ray induced heating, and the UV photodissociation and photodesorption. The grain-surface network combines the networks of Garrod \& Herbst (2006), Garrod et al. (2008) and Taquet et al. (2013), and the reaction probability rates of the methanol network are deduced from laboratory experiments (Hidaka et al. 2009). Figure 3 shows the main chemical pathways leading to the formation of methyl formate isotopologues on the grain surface. Methyl formate is assumed in the model to be formed through the radical-radical recombination of $\mathrm{HCO}$ and $\mathrm{CH}_{3} \mathrm{O}$ in warm $(20 \mathrm{~K}<T<80 \mathrm{~K})$ ices in the protostellar envelope (see Garrod \& Herbst 2006). Methyl formate deuterated isotopologues are also formed through similar reactions involving $\mathrm{HCO}, \mathrm{DCO}, \mathrm{CH}_{3} \mathrm{O}$, $\mathrm{CH}_{2} \mathrm{DO}$, and $\mathrm{CHD}_{2} \mathrm{O}$.

Table 2 shows the abundance ratios and $\mathrm{D} / \mathrm{H}$ ratio of methyl formate and formaldehyde isotopologues towards IRAS 16293A and $\mathrm{B}$, and in the model for the gas located in the inner region of the protostellar envelope (i.e. $R<50 \mathrm{AU}$ ) at two different times in the model labelled "early" and "late" corresponding to $\sim 2 \times 10^{4} \mathrm{yr}$ after the formation of the central protostar and at the end of the Class 0 stage $\left(\sim 1 \times 10^{5}\right.$ yr after the protostar formation), respectively. The deuteration enhancement occurs during the prestellar phase, when according to the model, the temperature is the lowest $(T<10 \mathrm{~K})$ in the inner prestellar core region and increases with radius as the density and the opacity decrease. At this stage, the temperature in the outer shells of the prestellar envelope is too high and the density too low for $\mathrm{CO}$ to freeze out. The presence of $\mathrm{CO}$ in the gas inhibits the exothermic gas-phase reaction $\mathrm{H}_{3}^{+}+\mathrm{HD} \rightarrow \mathrm{H}_{2} \mathrm{D}^{+}+\mathrm{HD}$, which is the main deuteration enhancement source at low temperatures. In addition, while the ice is built up, the deuteration of the freezing species increases with the time. This leads to an increasing $\mathrm{D} / \mathrm{H}$ ratio profile along the ice layers from the inside to the outside of the ice mantle. In addition, when the collapse begins and the object turns into a Class 0 protostar, the inner shells of the envelope are richer in deuterated molecules than the outer shells. As the collapse continues, the inner shells of the envelope fall onto the central object first and are replaced by the outer shells. The free-fall collapse assumed in the model induces a fast inward velocity of the envelope shells, limiting their time spent in the hot corino and hence the gas-phase chemistry after ice sublimation. Therefore, the $\mathrm{D} / \mathrm{H}$ ratio predicted in the gas phase of the hot corino decreases with time as it reflects the $\mathrm{D} / \mathrm{H}$ ratio produced in ices for envelope shells of increasing radii. Towards both components of IRAS 16293, the measured D/H ratio are of the same order of magnitude as the "early" time in the model. This suggests that the two protostars are still in their earliest evolutionary (Class 0 ) stages.

When the $\mathrm{D} / \mathrm{H}$ ratio of singly deuterated species is compared with their doubly deuterated forms, the model predicts the $\mathrm{D} / \mathrm{H}$ ratio to be similar between the two forms (i.e. 7.0 and $8.9 \%$ at the "early time" and 0.22 and $0.19 \%$ at the "late time" for the singly and the doubly deuterated isotopologues, respectively). However, towards IRAS $16293 \mathrm{~A}$ and $\mathrm{B}$, the $\mathrm{D} / \mathrm{H}$ ratio of doubly deuterated methyl formate are higher than the singly deuterated methyl formate by a factor of two to three. The gasphase formation pathways do not contribute significantly to the formation of methyl formate isotopologues in the model and are not able to reach the observed abundances in IRAS 16293. This suggests that several formation pathways on the grain surface are missing in the model.

Oba et al. $(2016 a, b)$ found that the H-D substitution reaction in the methyl group of ethanol and dimethyl ether could take place on ice grain surfaces at low temperatures. Similar reactions could also occur on the methyl group of methyl formate, increasing the $\mathrm{D} / \mathrm{H}$ ratio of $\mathrm{CHD}_{2} \mathrm{OCHO}$ with respect to $\mathrm{CH}_{2} \mathrm{DOCHO}$. In that way, the $\mathrm{D}-\mathrm{H}$ exchange could be more and more effective as the number of ice layers and the $\mathrm{D} / \mathrm{H}$ ratio of the gas-phase species increase. However, the $\mathrm{D} / \mathrm{H}$ ratio of $\mathrm{CH}_{2} \mathrm{DOCHO}$ and $\mathrm{CH}_{3} \mathrm{OCDO}$ are similar towards both IRAS $16293 \mathrm{~A}$ and B (see Table 2). Jørgensen et al. (2018) compared these results to the Taquet et al. (2014) model and suggested that there was no H-D substitution mechanism on the methyl group, enhancing 

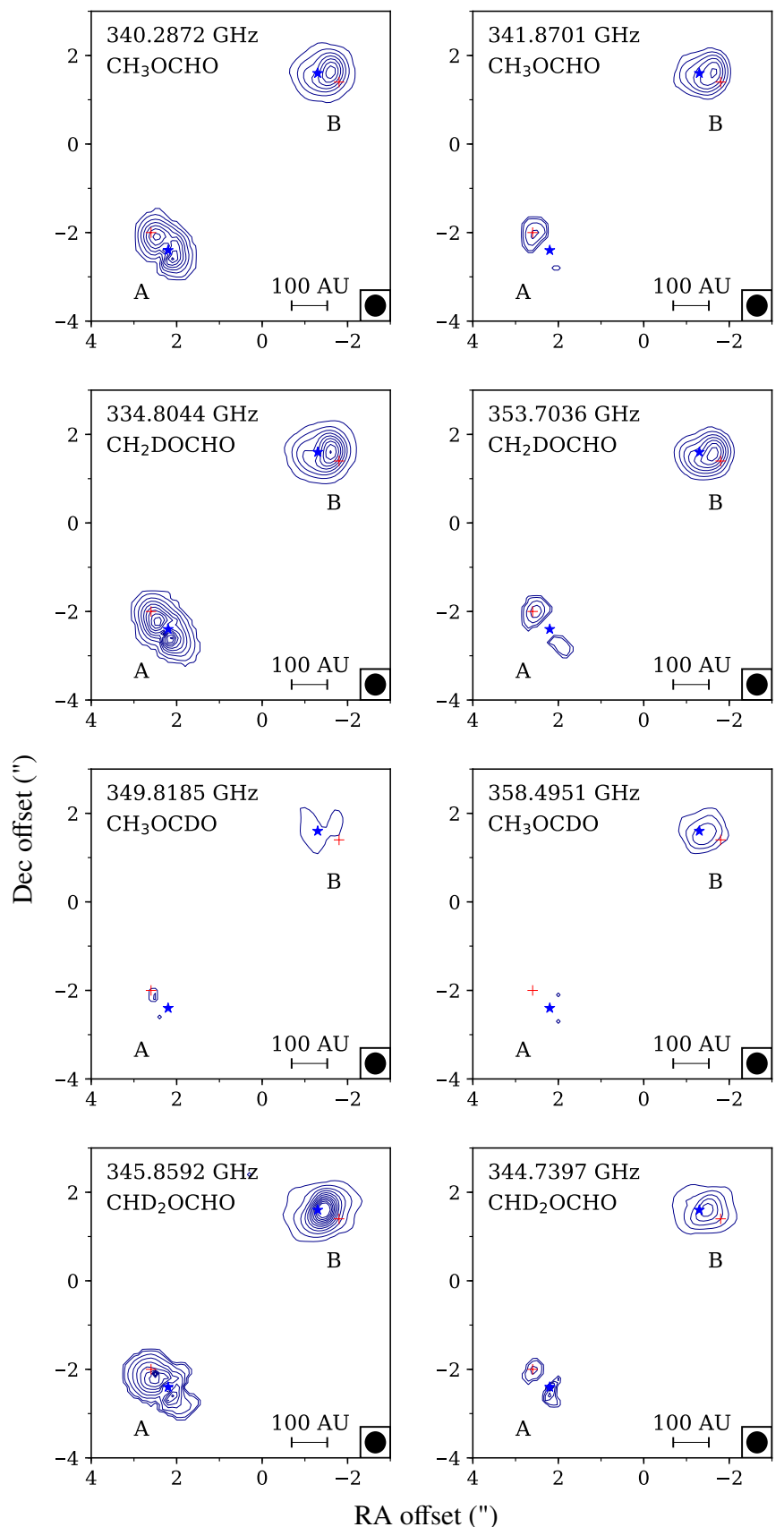

Fig. 2. VINE maps of two of the brightest transitions of each methyl formate isotopologue. Contour levels start at $3 \sigma$, with $\sigma=$ $10 \mathrm{mJy}$ beam ${ }^{-1} \mathrm{~km} \mathrm{~s}^{-1}$, and increase in steps of $3 \sigma$. Continuum peak positions and extracted spectra positions of IRAS 16293A and B are indicated with blue stars and red crosses, respectively.

the $\mathrm{D} / \mathrm{H}$ ratio of $\mathrm{CH}_{2} \mathrm{DOCHO}$ with respect to $\mathrm{CH}_{3} \mathrm{OCDO}$. In this case, the enhanced $\mathrm{D} / \mathrm{H}$ ratio of $\mathrm{CHD}_{2} \mathrm{OCHO}$ and $\mathrm{CH}_{2} \mathrm{DOCHO}$ could be directly inherited from their precursors $\mathrm{CHD}_{2} \mathrm{OH}$ and $\mathrm{CH}_{2} \mathrm{DOH}$, respectively. This is supported by the higher $\mathrm{D} / \mathrm{H}$ ratio of $\mathrm{D}_{2} \mathrm{CO}$ in comparison to $\mathrm{HDCO}$, the possible precursors of $\mathrm{CHD}_{2} \mathrm{OH}$ and $\mathrm{CH}_{2} \mathrm{DOH}$, respectively. Alternatively, if $\mathrm{H}-\mathrm{D}$ substitutions did occur on ice grain surfaces, increasing the $\mathrm{D} / \mathrm{H}$ ratio of $\mathrm{CH}_{2} \mathrm{DOCHO}$ and $\mathrm{CHD}_{2} \mathrm{OCHO}$ significantly, the $\mathrm{H}-\mathrm{D}$ substitution could also affect $\mathrm{CH}_{3} \mathrm{OCDO}$ at a close rate. Further experiments and modelling work are required to test this.

This new detection shows the importance of determining the $\mathrm{D} / \mathrm{H}$ ratio of singly and doubly deuterated species in order

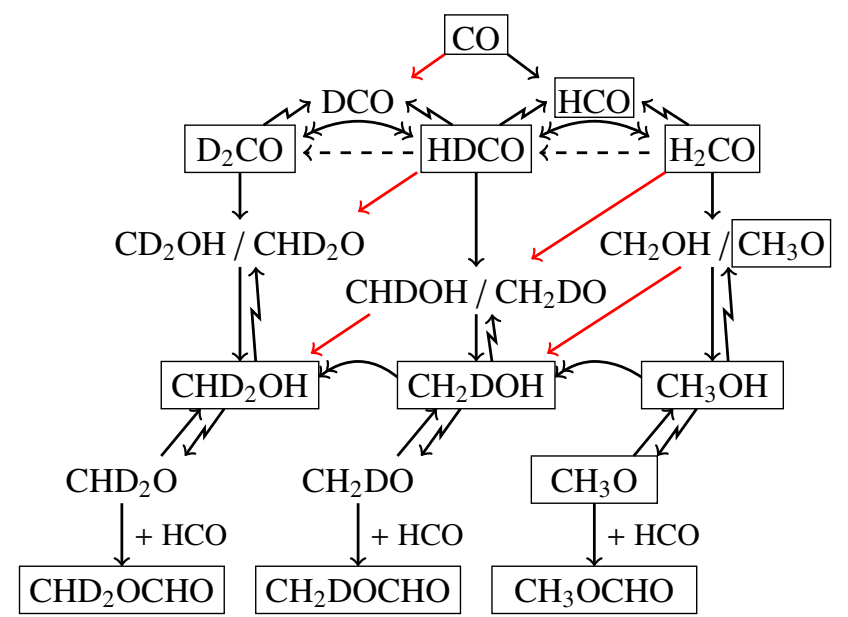

Fig. 3. Simplified chemical pathway for the formation of methyl formate and its isotopologues on the ice surface of dust grains. Species enclosed in a black box have been observed in the ISM. Normal arrows represent addition reactions, and hydrogenation when there is no radical noted near by, dashed lines are for H-D substitution, double-headed arrows show abstraction + addition reactions, and thunderbolt arrows represent photodissociation reactions. D-atom addition reactions are represented in red. This is a compilation of the studies of Garrod \& Herbst (2006), Hidaka et al. (2009), and Taquet et al. (2014).

to constrain their formation routes and times. However, the ratios observed in IRAS 16293 explore only the chemistry of two sources. In addition, the link between the deuteration level of methanol and methyl formate remains unclear and requires observations of multiply deuterated isotopologues of these species in a larger sample of protostellar sources, with similar sensitivity and angular resolution provided by interferometric arrays, such as ALMA.

Acknowledgements. This paper makes use of the following ALMA data: ADS/JAO.ALMA\#2013.1.00278.S. ALMA is a partnership of ESO (representing its member states), NSF (USA) and NINS (Japan), together with NRC (Canada) and NSC and ASIAA (Taiwan), in cooperation with the Republic of Chile. The Joint ALMA Observatory is operated by ESO, AUI/NRAO and NAOJ. The authors are grateful to Charlotte Vastel for the useful CASSIS software documentation about the synthetic spectrum formalism. The group of J. K. Jørgensen acknowledges support from the European Research Council (ERC) under the European Union's Horizon 2020 research and innovation programme (grant agreement No 646908) through ERC Consolidator Grant "S4F". Research at Centre for Star and Planet Formation is funded by the Danish National Research Foundation. V.T. acknowledges the financial support from the European Union's Horizon 2020 research and innovation programme under the Marie SklodowskaCurie grant agreement n. 664931. A.C. postdoctoral grant is funded by the ERC Starting Grant 3DICE (grant agreement 336474). M.N.D. acknowledges the financial support of the Center for Space and Habitability (CSH) Fellowship and the IAU Gruber Foundation Fellowship. This research has made use of NASA's Astrophysics Data System as well as community-developed core Python packages for astronomy and scientific computing including Astropy (Astropy Collaboration 2013), Scipy (Jones et al. 2001) and Matplotlib (Hunter 2007).

\section{References}

Astropy Collaboration (Robitaille, T. P., et al.) 2013, A\&A, 558, A33 Blake, G. A., van Dishoeck, E. F., Jansen, D. J., Groesbeck, T. D., \& Mundy, L. G. 1994, ApJ, 428, 680

Calcutt, H., Fiechter, M. R., Willis, E. R., et al. 2018a, A\&A, 617, A95

Calcutt, H., Jørgensen, J. K., Müller, H. S. P., et al. 2018b, A\&A, 616, A90

Carvajal, M., Kleiner, I., \& Demaison, J. 2010, ApJS, 190, 315

Caux, E., Kahane, C., Castets, A., et al. 2011, A\&A, 532, A23

Cazaux, S., Tielens, A. G. G. M., Ceccarelli, C., et al. 2003, ApJ, 593, L51

Ceccarelli, C. 2004, in Star Formation in the Interstellar Medium: In Honor of David Hollenbach, eds. D. Johnstone, F. C. Adams, D. N. C. Lin, D. A. Neufeeld, \& E. C. Ostriker, ASP Conf. Ser., 323, 195 
Ceccarelli, C., Caselli, P., Bockelée-Morvan, D., et al. 2014, Protostars and Planets VI, (Tucson,AZ: University of Arizona Press), 859

Chandler, C. J., Brogan, C. L., Shirley, Y. L., \& Loinard, L. 2005, ApJ, 632, 371

Coudert, L. H., Margulès, L., Huet, T. R., et al. 2012, A\&A, 543, A46

Coudert, L. H., Drouin, B. J., Tercero, B., et al. 2013, ApJ, 779, 119

Coutens, A., Jørgensen, J. K., van der Wiel, M. H. D., et al. 2016, A\&A, 590, L6

Drozdovskaya, M. N., van Dishoeck, E. F., Jørgensen, J. K., et al. 2018, MNRAS, 476, 4949

Duan, C., Carvajal, M., Yu, S., et al. 2015, A\&A, 576, A39

Dzib, S. A., Ortiz-León, G. N., Hernández-Gómez, A., et al. 2018, A\&A, 614, A20

Favre, C., Carvajal, M., Field, D., et al. 2014a, ApJS, 215, 25

Favre, C., Jørgensen, J. K., Field, D., et al. 2014b, ApJ, 790, 55

Garrod, R. T., \& Herbst, E. 2006, A\&A, 457, 927

Garrod, R. T., Widicus Weaver, S. L., \& Herbst, E. 2008, ApJ, 682, 283

Hasegawa, T. I., \& Herbst, E. 1993, MNRAS, 263, 589

Herbst, E., \& van Dishoeck E. F. 2009, ARA\&A, 47, 427

Hidaka, H., Watanabe, M., Kouchi, A., \& Watanabe, N. 2009, ApJ, 702, 291

Hunter, J. D. 2007, Comput. Sci. Eng., 9, 90

Ilyushin, V., Kryvda, A., \& Alekseev, E. 2009, J. Mol. Spectr., 255, 32

Ivezic, Z., \& Elitzur, M. 1997, MNRAS, 287, 799

Jones, E., Oliphant, T., Peterson, P., et al. 2001, SciPy: Open source scientific tools for Python

Jørgensen, J. K., Favre, C., Bisschop, S. E., et al. 2012, ApJ, 757, L4

Jørgensen, J. K., van der Wiel, M. H. D., Coutens, A., et al. 2016, A\&A, 595, A 117

Jørgensen, J. K., Müller, H. S. P., Calcutt, H., et al. 2018, A\&A, 620, A170

Ligterink, N. F. W., Coutens, A., Kofman, V., et al. 2017, MNRAS, 469, 2219

Loinard, L., Castets, A., Ceccarelli, C., et al. 2000, A\&A, 359, 1169

Lykke, J. M., Coutens, A., Jørgensen, J. K., et al. 2017, A\&A, 597, A53
Maeda, A., De Lucia, F. C., \& Herbst, E. 2008a, J. Mol. Spectr., 251, 293

Maeda, A., Medvedev, I. R., De Lucia, F. C., Herbst, E., \& Groner, P. 2008b, ApJS, 175, 138

Müller, H. S. P., Schlöder, F., Stutzki, J., \& Winnewisser, G. 2005, J. Mol. Struct., 742,215

Müller, H. S. P., Thorwirth, S., Roth, D. A., \& Winnewisser, G. 2001, A\&A, 370, L49

Oba, Y., Osaka, K., Chigai, T., Kouchi, A., \& Watanabe, N. 2016a, MNRAS, 462, 689

Oba, Y., Watanabe, N., \& Kouchi, A. 2016b, Chem. Phys. Lett., 662, 14

Oesterling, L. C., Albert, S., De Lucia, F. C., Sastry, K. V. L. N., \& Herbst, E. 1999, ApJ, 521, 255

Parise, B., Ceccarelli, C., Tielens, A. G. G. M., et al. 2002, A\&A, 393, L49

Parise, B., Ceccarelli, C., Tielens, A. G. G. M., et al. 2006, A\&A, 453, 949

Pech, G., Loinard, L., Chandler, C. J., et al. 2010, ApJ, 712, 1403

Persson, M. V., Jørgensen, J. K., Müller, H. S. P., et al. 2018, A\&A, 610, A54

Pickett, H. M., Poynter, R. L., Cohen, E. A., et al. 1998, J. Quant. Spectr. Rad. Transf., 60, 883

Pineda, J. E., Maury, A. J., Fuller, G. A., et al. 2012, A\&A, 544, L7

Plummer, G. M., Herbst, E., De Lucia, F., \& Blake, G. A. 1984, ApJS, 55, 633

Prodanović, T., Steigman, G., \& Fields, B. D. 2010, MNRAS, 406, 1108

Punanova, A., Caselli, P., Pon, A., Belloche, A., \& André, P. 2016, A\&A, 587, A118

Taquet, V., Ceccarelli, C., \& Kahane, C. 2012, A\&A, 538, A42

Taquet, V., Peters, P. S., Kahane, C., et al. 2013, A\&A, 550, A127

Taquet, V., Charnley, S. B., \& Sipilä, O. 2014, ApJ, 791, 1

van Dishoeck, E. F., Blake, G. A., Jansen, D. J., \& Groesbeck, T. D. 1995, ApJ, 447, 760

Willaert, F., Møllendal, H., Alekseev, E., et al. 2006, J. Mol. Struct., 795, 4

Wootten, A. 1989, ApJ, 337, 858 


\section{Appendix A: Spectroscopic data}

The spectroscopic data are from the Jet Propulsion Laboratory catalog (JPL; Pickett et al. 1998) for $\mathrm{CH}_{3} \mathrm{OCHO}$ and from the Cologne Database for Molecular Spectroscopy (CDMS; Müller et al. 2001, 2005) entry for $\mathrm{CH}_{3} \mathrm{O}^{13} \mathrm{CHO}$. $\mathrm{CH}_{3} \mathrm{OCHO}$ data are based on Ilyushin et al. (2009) with data in the range of the PILS survey from Plummer et al. (1984), Oesterling et al. (1999), and Maeda et al. (2008a). The $\mathrm{CH}_{3} \mathrm{O}^{13} \mathrm{CHO}$ entry is based on Carvajal et al. (2010), with measured data in our range from Willaert et al. (2006) and Maeda et al. (2008a,b). The spectroscopic data and the partition function for $\mathrm{CH}_{2}$ DOCHO are taken from Coudert et al. (2013), those for $\mathrm{CH}_{3}$ OCDO are taken from Duan et al. (2015), and those for the doubly deuterated $\mathrm{CHD}_{2} \mathrm{OCHO}$ are provided by Coudert et al. (2012). The partition function for $\mathrm{CH}_{3} \mathrm{OCDO}$ is assumed to be the same as for $\mathrm{CH}_{2} \mathrm{DOCHO}$. The contribution from the excited vibrational levels to the partition function of $\mathrm{CH}_{3} \mathrm{O}^{13} \mathrm{CHO}$ and the main isotopologue are determined by Favre et al. (2014a) and are only included in the $\mathrm{CH}_{3} \mathrm{O}^{13} \mathrm{CHO}$ database entry. In this study, the vibrational contribution for the partition function of deuterated forms is assumed to be the same as for ${ }^{13} \mathrm{C}$-methyl formate. The contribution from the excited vibrational levels is 1.11 and 2.51 for $\mathrm{CH}_{3} \mathrm{OCHO}$ and 1.31 and 3.85 for both $\mathrm{CH}_{2} \mathrm{DOCHO}$ and $\mathrm{CHD}_{2} \mathrm{OCHO}$ at $T_{\mathrm{ex}}=115 \mathrm{~K}$ and $300 \mathrm{~K}$, respectively.

\section{Appendix B: $\mathrm{D} / \mathrm{H}$ ratio versus abundance ratio}

In the literature, the abundance ratio between the deuterated isotopologue and the main conformer is often presented as the deuterium fractionation. However, when the chemical group containing $\mathrm{D}$ isotopes has at least two bonds to $\mathrm{H}$ or $\mathrm{D}$ atoms, it is not possible to distinguish between the different arrangement of $\mathrm{H}$ and $\mathrm{D}$ and hence to compare the deuteration between different functional groups of the same species (e.g. between $-\mathrm{CH}_{3}$ and $-\mathrm{CHO}$ ).

The probability of having a D atom in a particular site in a chemical group is independent of the other potential sites. Then, the number of complete and undistinguishable chemical groups with $i$ deuterium atoms on $n$ sites is the number of
Table B.1. Relations between the abundance ratio and the $\mathrm{D} / \mathrm{H}$ ratio.

\begin{tabular}{|c|c|c|}
\hline Abundance ratio & & $\mathrm{D} / \mathrm{H}$ ratio prescription \\
\hline $\mathrm{HDCO} / \mathrm{H}_{2} \mathrm{CO}$ & $=$ & $2(\mathrm{D} / \mathrm{H})$ \\
\hline $\mathrm{D}_{2} \mathrm{CO} / \mathrm{H}_{2} \mathrm{CO}$ & $=$ & $(\mathrm{D} / \mathrm{H})^{2}$ \\
\hline $\mathrm{D}_{2} \mathrm{CO} / \mathrm{HDCO}$ & $=$ & $1 / 2(\mathrm{D} / \mathrm{H})_{\mathrm{HDCO}}$ \\
\hline $\mathrm{CH}_{2} \mathrm{DOH} / \mathrm{CH}_{3} \mathrm{OH}$ & $=$ & $3(\mathrm{D} / \mathrm{H})$ \\
\hline $\mathrm{CHD}_{2} \mathrm{OH} / \mathrm{CH}_{3} \mathrm{OH}$ & $=$ & $3(\mathrm{D} / \mathrm{H})^{2}$ \\
\hline $\mathrm{CHD}_{2} \mathrm{OH} / \mathrm{CH}_{2} \mathrm{DOH}$ & $=$ & $(\mathrm{D} / \mathrm{H}) \mathrm{CH}_{2} \mathrm{DOH}$ \\
\hline $\mathrm{CH}_{2} \mathrm{DOCHO} / \mathrm{CH}_{3} \mathrm{OCHO}$ & $=$ & $3(\mathrm{D} / \mathrm{H})$ \\
\hline $\mathrm{CHD}_{2} \mathrm{OCHO} / \mathrm{CH}_{3} \mathrm{OCHO}$ & $=$ & $3(\mathrm{D} / \mathrm{H})^{2}$ \\
\hline $\mathrm{CHD}_{2} \mathrm{OCHO} / \mathrm{CH}_{2} \mathrm{DOCHO}$ & $=$ & $(\mathrm{D} / \mathrm{H}) \mathrm{CH}_{2} \mathrm{DOCHO}$ \\
\hline
\end{tabular}

arrangements of the deuterium atoms and the rest in hydrogen atoms. This leads to the relation between the abundance ratio and the $\mathrm{D} / \mathrm{H}$ ratio:

$\frac{\mathrm{XH}_{n-i} \mathrm{D}_{i}}{\mathrm{XH}_{n}}=\left(\begin{array}{l}n \\ i\end{array}\right)\left(\frac{\mathrm{D}}{\mathrm{H}}\right)^{i}$,

where $n$ is the number of valence of the $\mathrm{X}$ group, $i$ is the number of $\mathrm{D}$ attached to the $\mathrm{X}$ group, and $\left(\begin{array}{l}n \\ i\end{array}\right)=\frac{n !}{i !(n-i) !}$ is the number of arrangements of $i$ into $n$. This leads to

$\frac{\mathrm{XH}_{n-i} \mathrm{D}_{i}}{\mathrm{XH}_{n-j} \mathrm{D}_{j}}=\frac{\left(\begin{array}{c}n \\ i\end{array}\right)}{\left(\begin{array}{c}n \\ j\end{array}\right)}\left(\frac{\mathrm{D}}{\mathrm{H}}\right)^{i-j}, i>j \geq 0$.

Table B.1 provides the different relations between abundance ratio and $\mathrm{D} / \mathrm{H}$ ratio used in this paper. It is necessary to have the same number of deuterium atoms in the functional groups in the reference species (i.e. the bottom species in the ratio). For example, the $\mathrm{D} / \mathrm{H}$ ratio of $\mathrm{CHD}_{2} \mathrm{OCHO}$ with respect to $\mathrm{CH}_{3} \mathrm{OCHO}$ and $\mathrm{CH}_{2}$ DOCHO gives two different values. Based on the probabilistic definition of the $\mathrm{D} / \mathrm{H}$ ratio, this is similar to comparing an independent probability of having $A$ with the probability of having $A$ knowing $B$. 


\section{Appendix C: Velocity-corrected integrated emission maps}

This section shows the velocity-corrected integrated emission maps (VINE maps) of the brightest unblended lines of $\mathrm{CH}_{3} \mathrm{OCHO}$, $\mathrm{CH}_{2} \mathrm{DOCHO}, \mathrm{CH}_{3} \mathrm{OCDO}$, and $\mathrm{CHD}_{2} \mathrm{OCHO}$, with three spectra for each source extracted at the continuum peak positions at a 0 .' 3 offset position and 0.' 6 offset position ( 0.5 for source B).

VINE map
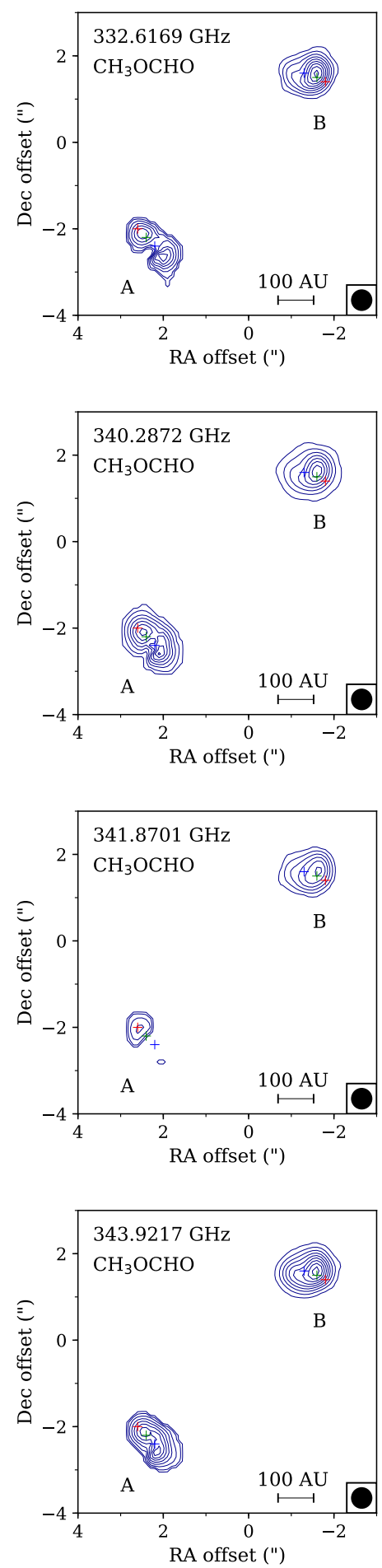

IRAS16293A
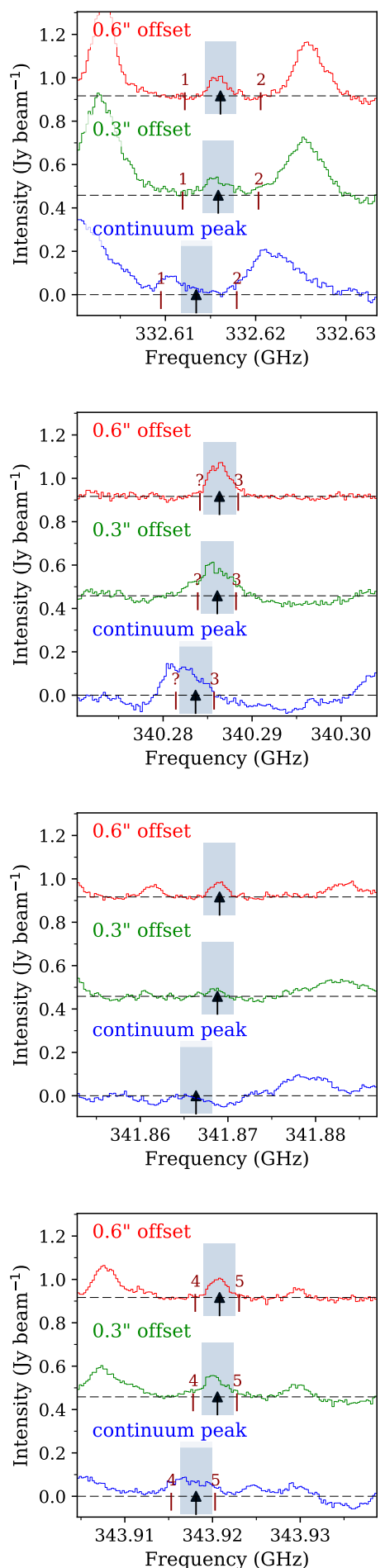

IRAS16293B
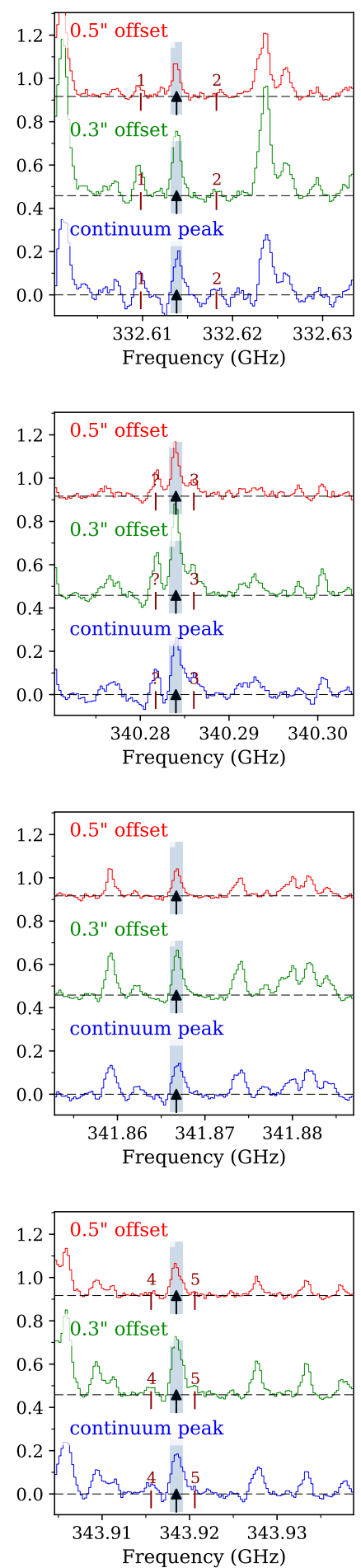

Fig. C.1. VINE maps of the brightest $\mathrm{CH}_{3} \mathrm{OCHO}$ transitions. Contour levels start at $3 \sigma$ and increase in steps of $3 \sigma$, excepted for the $340287 \mathrm{GHz}$ line, for which the step is $6 \sigma$. The integration range is indicated with a grey rectangle on spectra extracted from three positions, marked with coloured crosses on the map: the continuum peak position in blue, the 0.'3 offset position in green, and the 0.'6 ( 0.5 for source B) offset position in red, towards IRAS 16293A (middle panels) and B (right panels). The black arrow indicates the rest frequency of the mapped transition. Numbered indicators correspond to other species with a line close to the transition of interest: $(1) \mathrm{CH}_{2}(\mathrm{OH}) \mathrm{CHO},(2) \mathrm{gGg}^{\prime}-\left(\mathrm{CH}_{2} \mathrm{OH}\right)_{2},(3) \mathrm{CH}_{3} \mathrm{CDO}$, (4) g-n- $\mathrm{C}_{3} \mathrm{H}_{7} \mathrm{CN}$, (5) $\mathrm{S}_{2} \mathrm{O}\left(\mathrm{E}_{\mathrm{u}}=1058 \mathrm{~K}\right)$, (?) Unidentified. 
S. Manigand et al.: First detection of doubly deuterated methyl formate $\left(\mathrm{CHD}_{2} \mathrm{OCHO}\right)$ in the ISM

VINE map
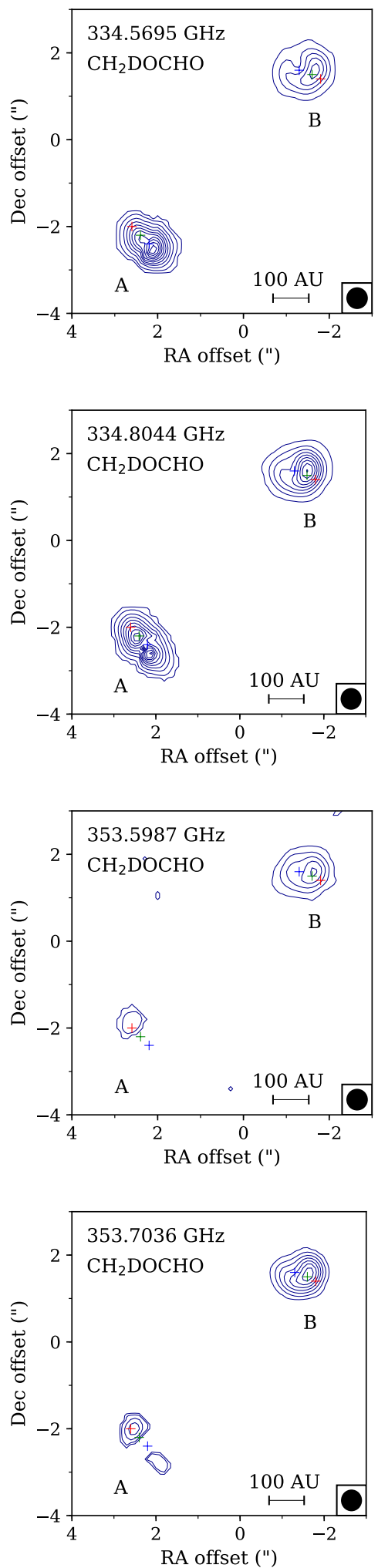

IRAS16293A
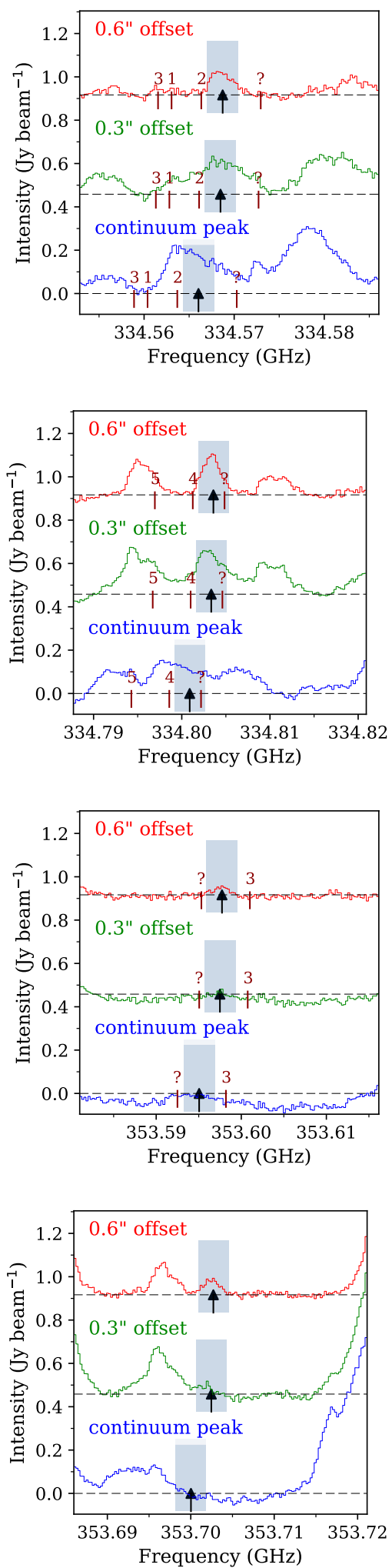

IRAS16293B
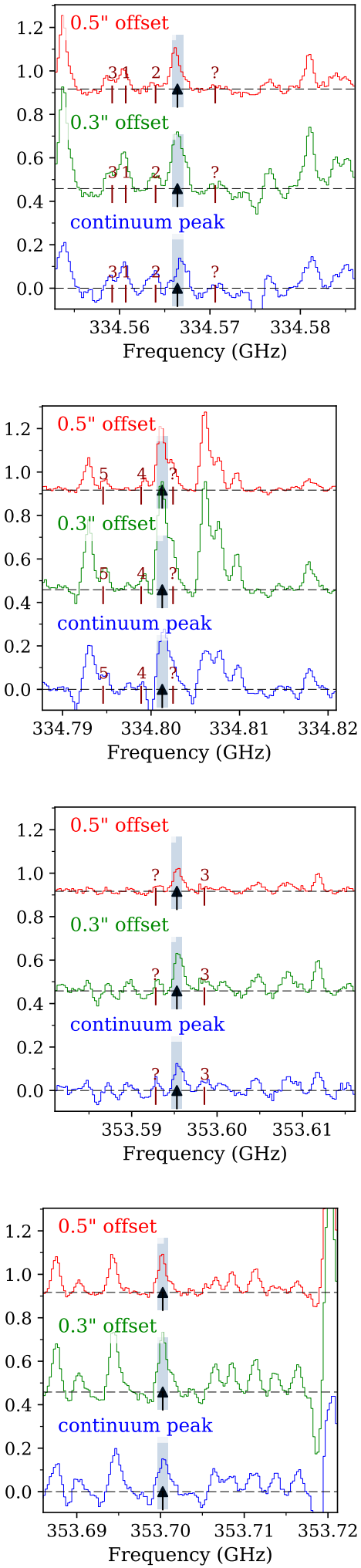

Fig. C.2. VINE maps of the brightest $\mathrm{CH}_{2}$ DOCHO transitions. Contour levels start at $3 \sigma$ and increase in steps of $3 \sigma$ for the 353599 and $353704 \mathrm{GHz}$ lines and $6 \sigma$ for the 334569 and $334804 \mathrm{GHz}$ lines. The integration range is indicated with a grey rectangle on spectra extracted from three positions, marked with coloured crosses on the map: the continuum peak position in blue, the $0{ }^{\prime} .3$ offset position in green, and the 0.' 6 (0'.5 for source B) offset position in red, towards IRAS 16293A (middle panels) and B (right panels). The black arrow indicates the rest frequency of the mapped transition. Numbered indicators correspond to other species with a line close to the transition of interest: $(1) \mathrm{CH}_{2}(\mathrm{OH}) \mathrm{CHO}$, (2) $\mathrm{CH}_{3} \mathrm{CH}_{2} \mathrm{OH}$, (3) $\mathrm{CH}_{3} \mathrm{O}^{13} \mathrm{CHO}$, (4) $\mathrm{CH}_{3} \mathrm{CHO}$, (5) $\mathrm{CH}_{3} \mathrm{COCH}_{3}$, (?) Unidentified. 
VINE map
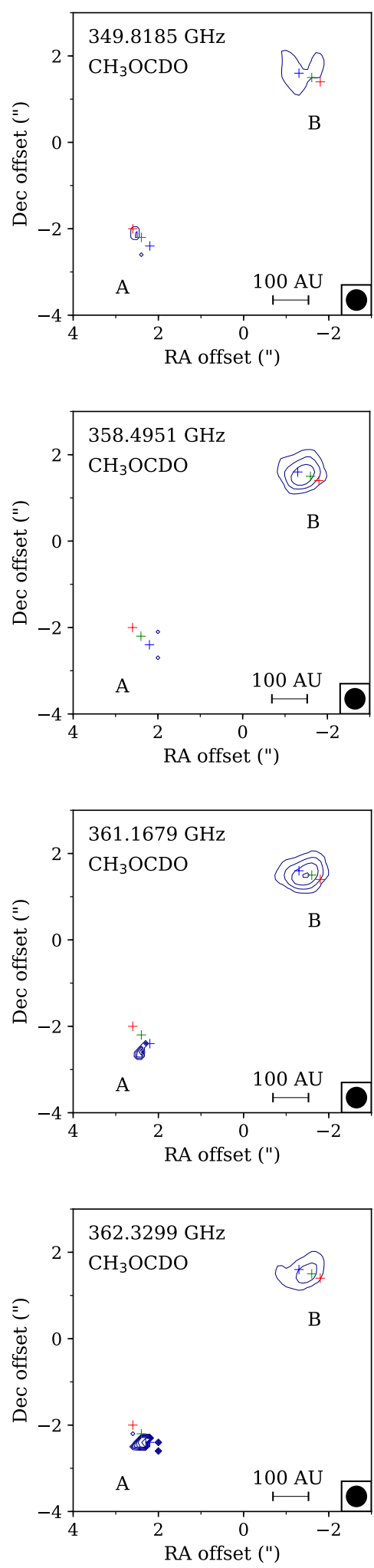

IRAS16293A
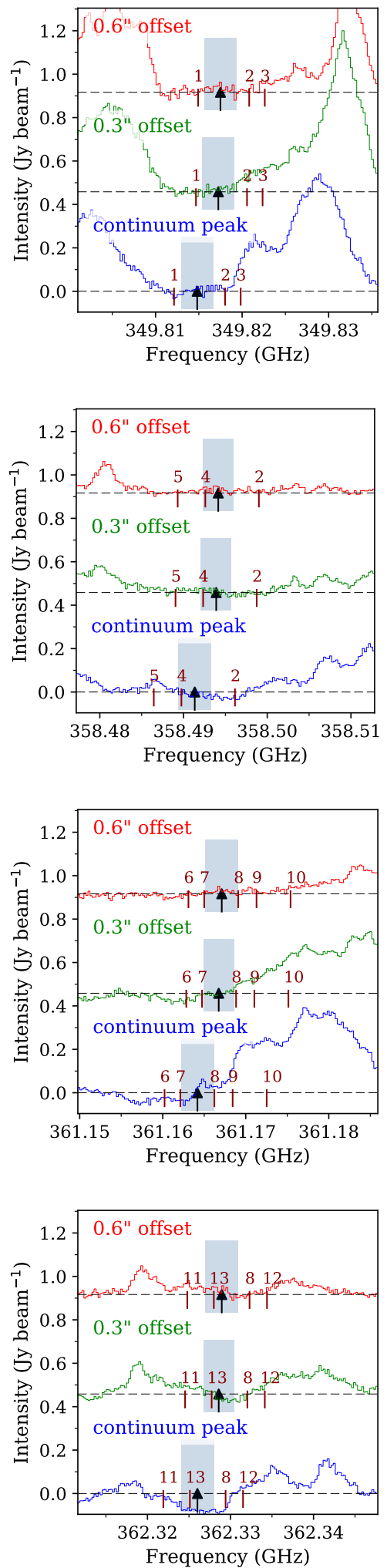

IRAS16293B
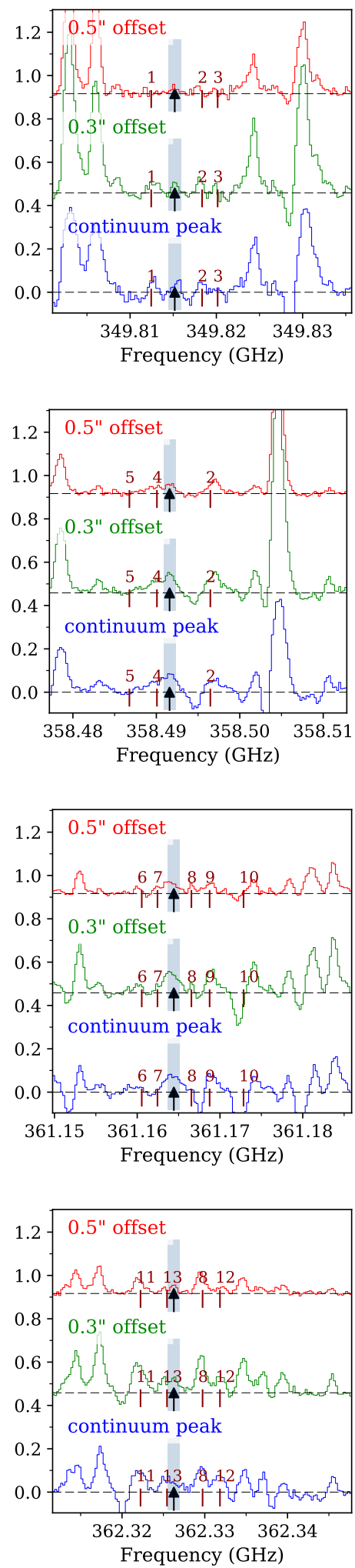

Fig. C.3. VINE maps of the brightest $\mathrm{CH}_{3} \mathrm{OCDO}$ transitions. Contour levels start at $3 \sigma$ and increase in steps of $3 \sigma$. The integration range is indicated with a grey rectangle on spectra extracted from three positions, marked with coloured crosses on the map: the continuum peak position in blue, the 0.'3 offset position in green, and the 0'.6 (0'.5 for the B source) offset position in red, towards IRAS 16293A (middle panels) and B (right panels). The black arrow indicates the rest frequency of the mapped transition. Numbered indicators correspond to other species with a line close to the transition of interest: (1) $\mathrm{H}^{13} \mathrm{COOH},(2) \mathrm{gGa}-\left(\mathrm{CH}_{2} \mathrm{OH}\right)_{2},(3) \mathrm{CH}_{3} \mathrm{OCH}_{3}$, (4) $\mathrm{CH}_{3} \mathrm{CH}_{2} \mathrm{OH}$, (5) HSC, (6) ${ }^{13} \mathrm{CH}_{2} \mathrm{CHCN}$, (7) $\mathrm{CH}_{3} \mathrm{CHO}$, (8) $\mathrm{CH}_{3} \mathrm{O}^{13} \mathrm{CHO}$, (9) $\mathrm{CH}_{2}(\mathrm{OH})^{13} \mathrm{CHO}$, (10) $\mathrm{CH}_{2} \mathrm{DOH}$, (11) $\mathrm{CH}_{2}(\mathrm{OH}) \mathrm{CHO}$, (12) $\mathrm{CH}_{3} \mathrm{OCHO}$, (13) $\mathrm{CH}_{2} \mathrm{CH}^{13} \mathrm{CN}$. 
S. Manigand et al.: First detection of doubly deuterated methyl formate $\left(\mathrm{CHD}_{2} \mathrm{OCHO}\right)$ in the ISM

VINE map
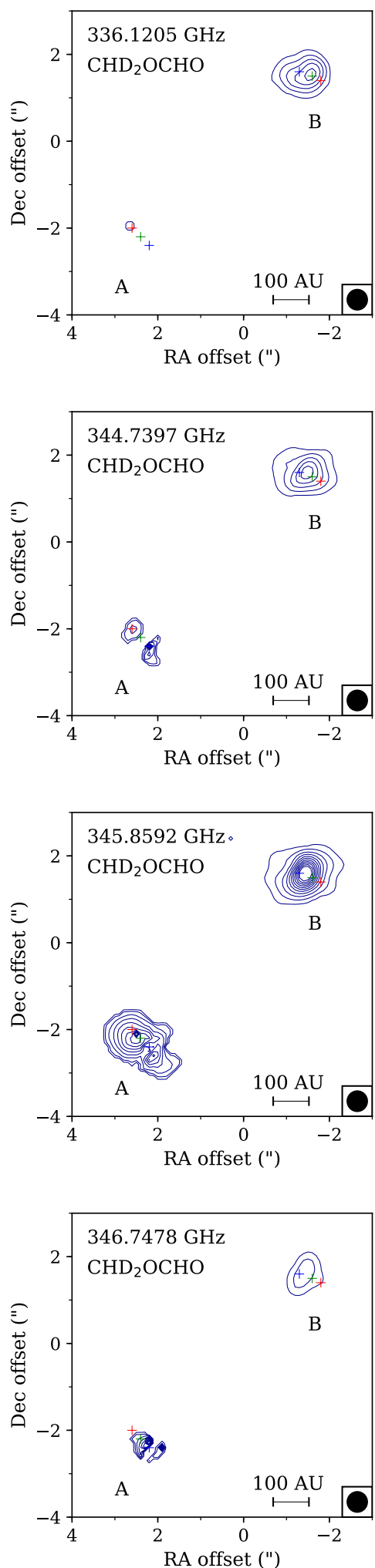

IRAS16293A
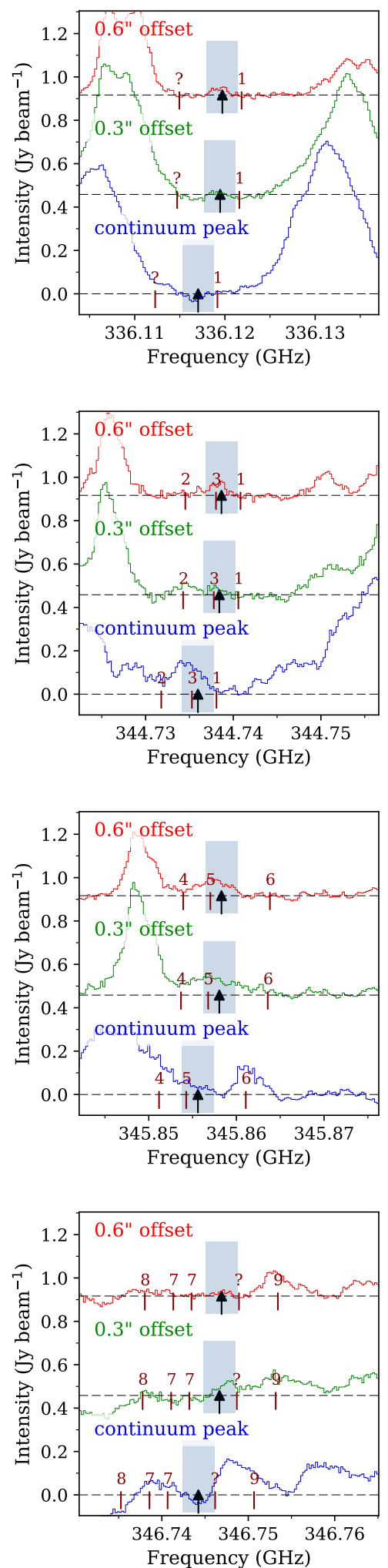

IRAS16293B
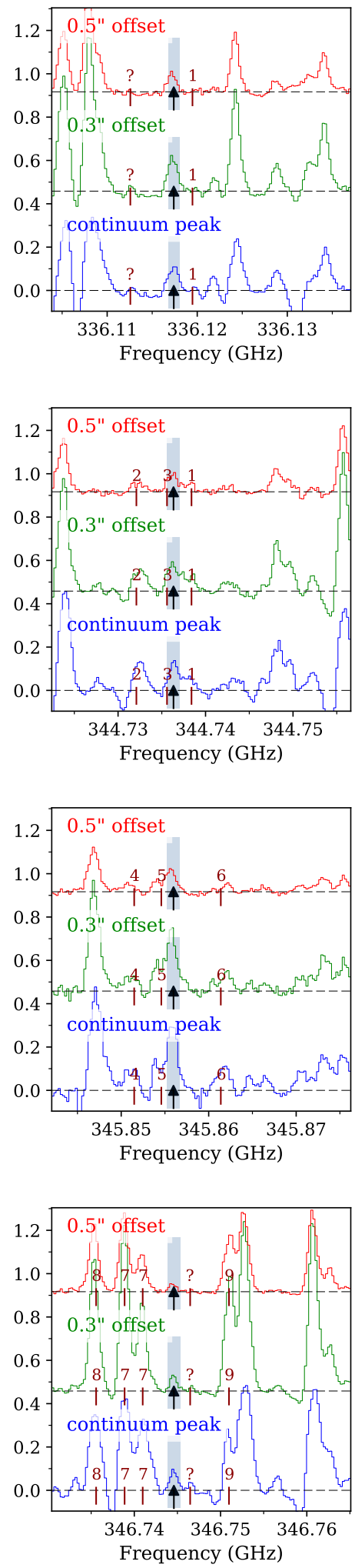

Fig. C.4. VINE maps of the brightest $\mathrm{CHD}_{2} \mathrm{OCHO}$ transitions. Contour levels start at $3 \sigma$ and increase in steps of $3 \sigma$. The integration range is indicated with a grey rectangle on spectra extracted from three positions, marked with coloured crosses on the map: the continuum peak position in blue, 0.'3 offset position in green and 0.'6 (0'5 for source B) offset position in red, towards IRAS 16293A (middle panels) and B (right panels). The black arrow indicates the rest frequency of the mapped transition. Numbered indicators correspond to other species with a line close to the transition of interest: (1) aGg'- $\left(\mathrm{CH}_{2} \mathrm{OH}\right)_{2},(2) \mathrm{CH}_{3} \mathrm{OCHO}$, (3) $\mathrm{CH}_{3} \mathrm{O}^{13} \mathrm{CHO}$, (4) a-a- $\mathrm{CH}_{2} \mathrm{DCH}_{2} \mathrm{OH}$, (5) $\mathrm{NH}_{2} \mathrm{CHO}_{2}$, (6) ${ }^{13} \mathrm{CH}_{3} \mathrm{OH}$, (7) $\mathrm{CH}_{3} \mathrm{CHO}_{\text {, }}$ (8) $\mathrm{HDCO},(9) \mathrm{CH}_{3} \mathrm{COCH}_{3}$, (?) Unidentified. 


\section{Appendix D: $\mathrm{CH}_{3} \mathrm{OCHO}, \mathrm{CH}_{2}$ DOCHO, and $\mathrm{CH}_{3} \mathrm{OCDO}$ towards IRAS 16293A}

This section presents the brightest fitted lines for $\mathrm{CH}_{3} \mathrm{OCHO}, \mathrm{CH}_{2} \mathrm{DOCHO}$, and $\mathrm{CH}_{3} \mathrm{OCDO}$.

\section{$\mathrm{CH}_{3} \mathrm{OCHO}$}

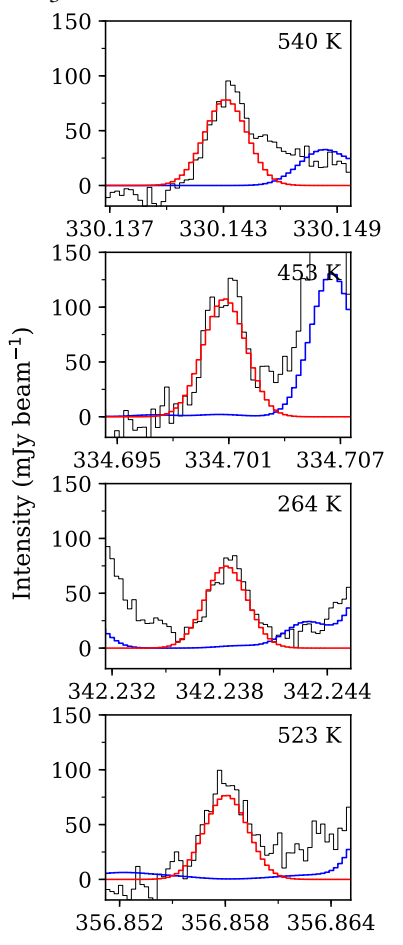

\section{$\mathrm{CH}_{2} \mathrm{DOCHO}$}

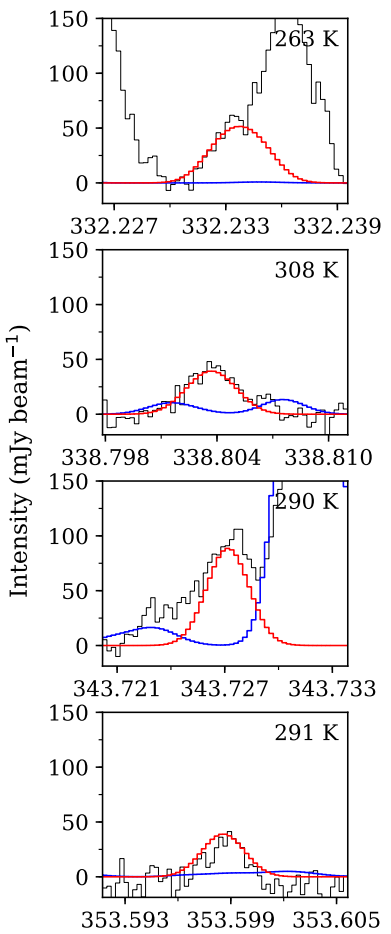

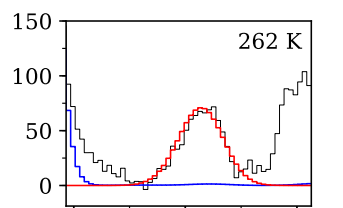

$\begin{array}{lll}330.197 & 330.203 & 330.209\end{array}$
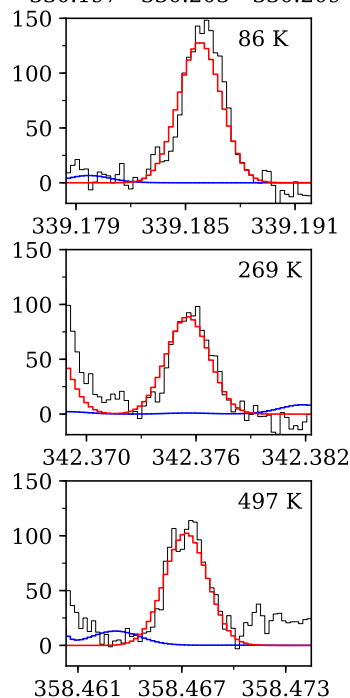

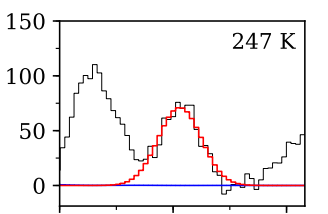

$\begin{array}{lll}330.647 & 330.653 & 330.659\end{array}$
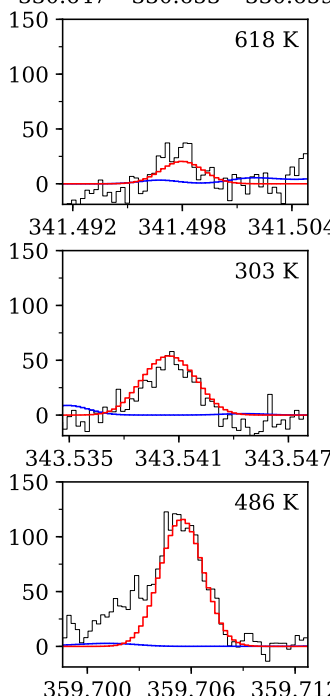

$\begin{array}{llll}359.700 & 359.706 & 359.712\end{array}$

Frequency (GHz)

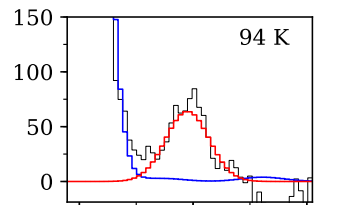

$\begin{array}{lll}333.967 & 333.973 & 333.979\end{array}$
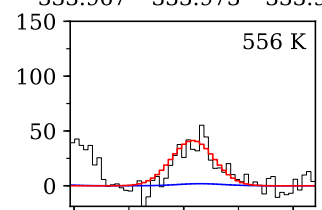

$\begin{array}{lll}341.540 & 341.546 \quad 341.552\end{array}$
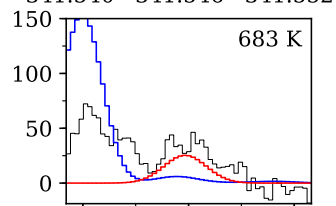

$\begin{array}{lll}354.077 & 354.083 & 354.089\end{array}$
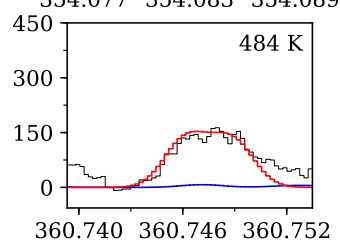

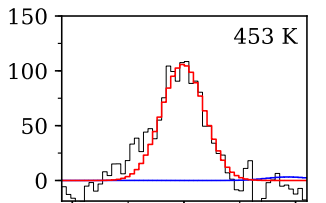

$\begin{array}{lll}334.068 & 334.074 & 334.080\end{array}$
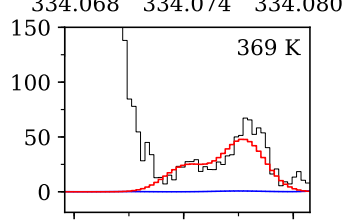

$\begin{array}{lll}341.584 & 341.590 & 341.596\end{array}$
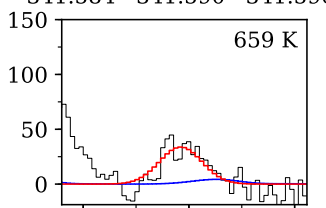

$\begin{array}{llll}354.172 & 354.178 \quad 354.184\end{array}$

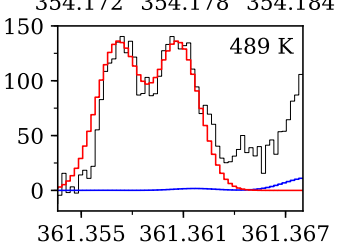

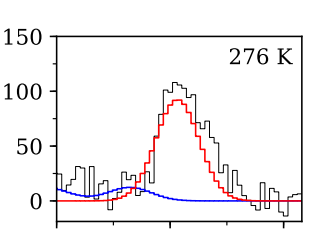

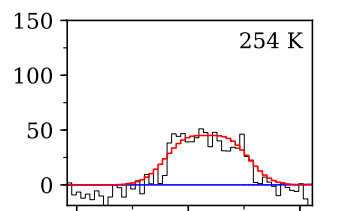

$\begin{array}{lll}334.563 & 334.569 & 334.575\end{array}$

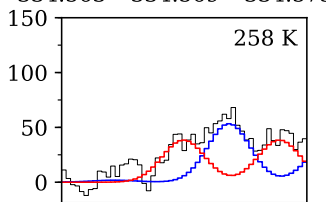

$\begin{array}{lll}342.124 & 342.130 & 342.136\end{array}$
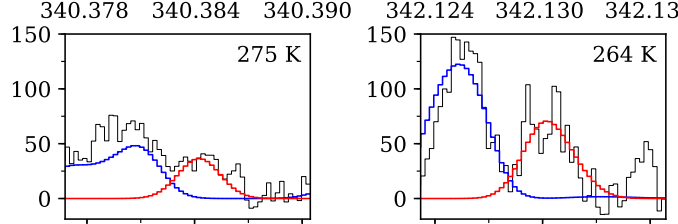

$\begin{array}{llll}343.832 & 343.838 & 343.844\end{array}$
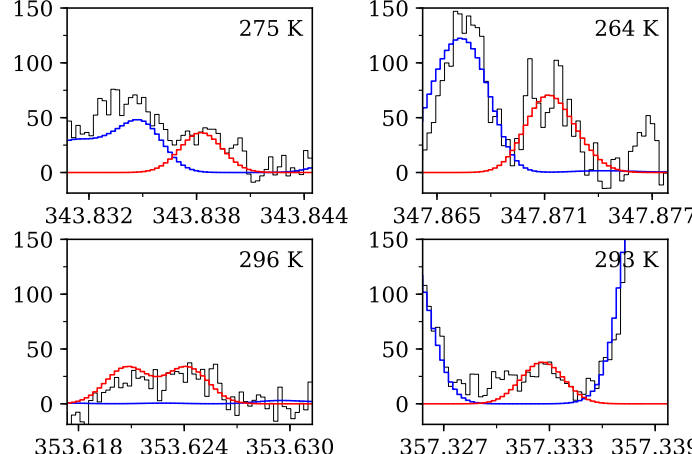

$\begin{array}{llll}347.865 & 347.871 & 347.877\end{array}$
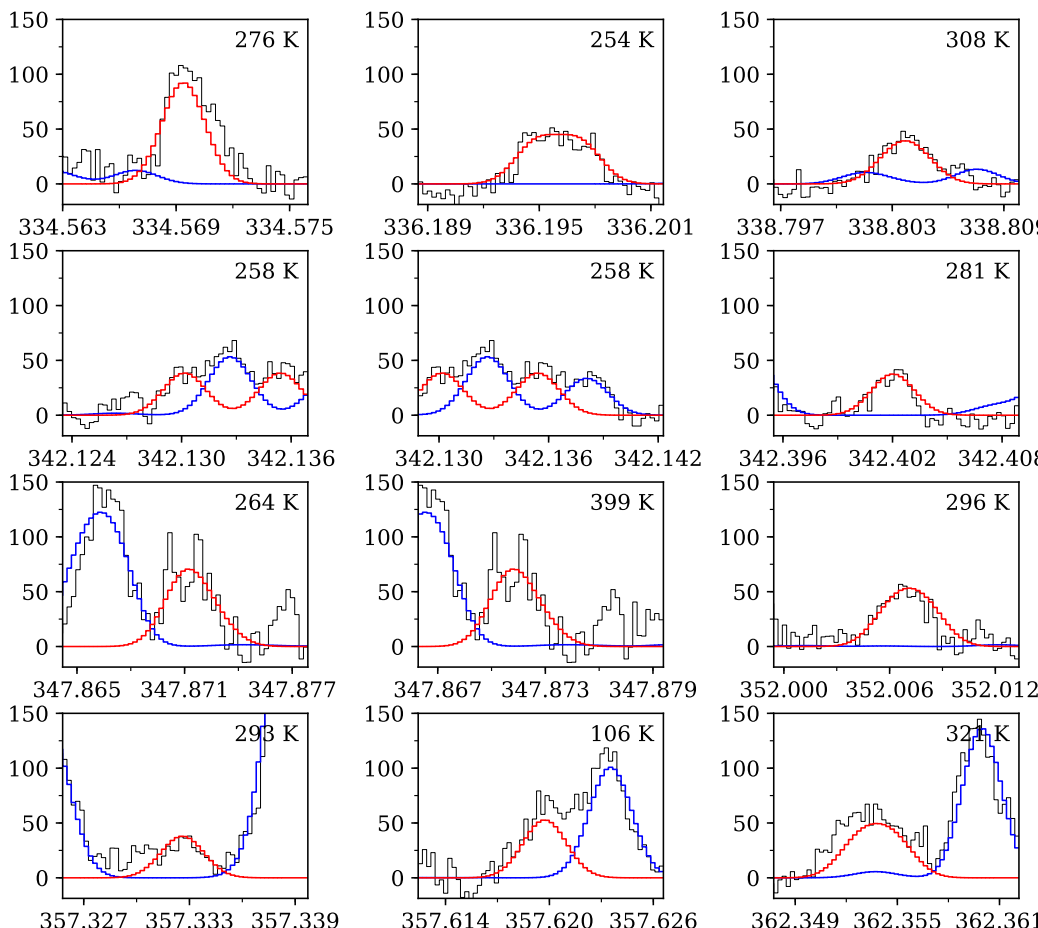

$\begin{array}{lll}338.797 & 338.803 & 338.809\end{array}$

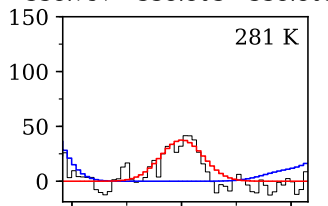

$\begin{array}{rrr}342.130 & 342.136 & 342.142\end{array}$

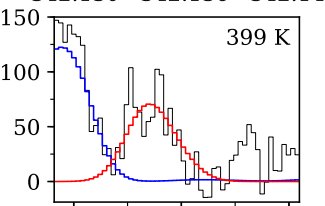

$\begin{array}{lll}342.396 & 342.402 & 342.408\end{array}$
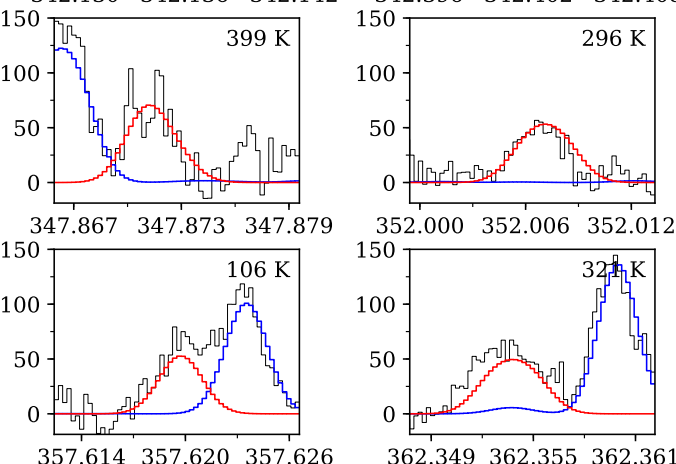

$\begin{array}{llll}352.000 & 352.006 & 352.012\end{array}$

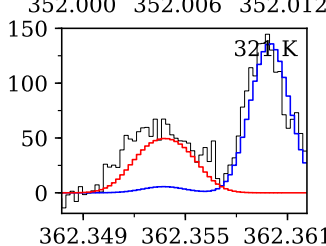

Frequency $(\mathrm{GHz})$

Fig. D.1. Twenty bright transitions of $\mathrm{CH}_{3} \mathrm{OCHO}$ (top panels) and $\mathrm{CH}_{2}$ DOCHO (bottom panels) towards IRAS $16293 \mathrm{~A}$. The synthetic spectra are over-plotted in red, a reference spectrum is shown in blue, and the data are presented in black. The upper-level energy of each transition is indicated in the top right corner of each plot. 


\section{$\mathrm{CH}_{3} \mathrm{OCDO}$}

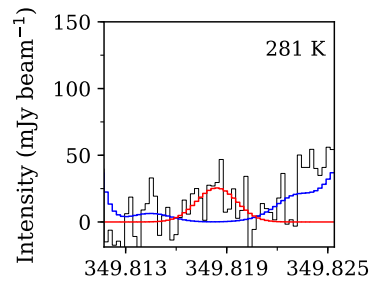

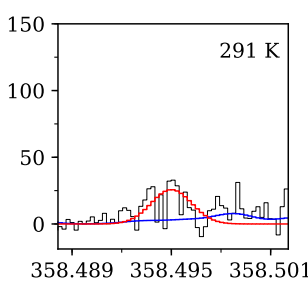

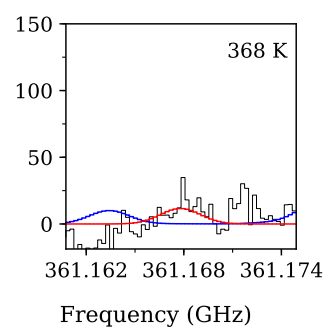

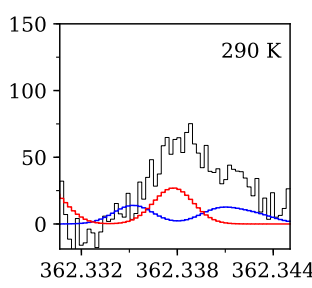

Fig. D.2. Five brightest transitions of $\mathrm{CH}_{3} \mathrm{OCDO}$ towards IRAS 16293A. The synthetic spectra are over-plotted in red, a reference spectrum is shown in blue, and the data are presented in black. The upper-level energy of each transition is indicated in the top right corner of each plot.

\section{Appendix E: Observed $\mathrm{CHD}_{2} \mathrm{OCHO}$ lines}

This section shows the brightest fitted lines for $\mathrm{CHD}_{2} \mathrm{OCHO}$ towards IRAS $16293 \mathrm{~A}$ and B and the list of plotted transitions. Most of the lines are a combination of unresolved hyperfine transitions, explaining the size of the list compared to the number of lines in the spectra.

IRAS $16293-2422$ A
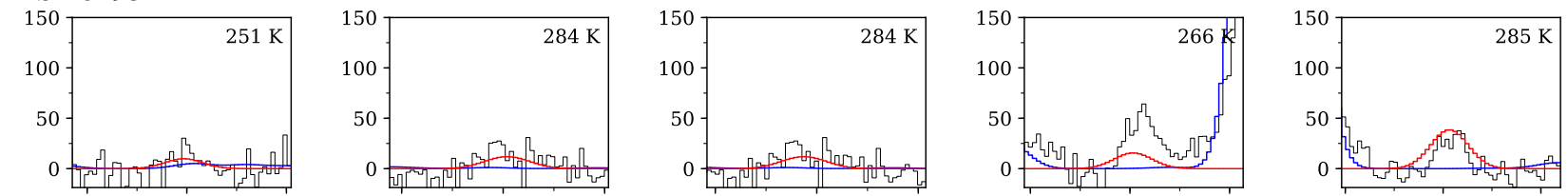

न $332.863 \quad 332.869 \quad 332.875$

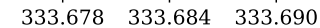

$333.679 \quad 333.685 \quad 333.691$
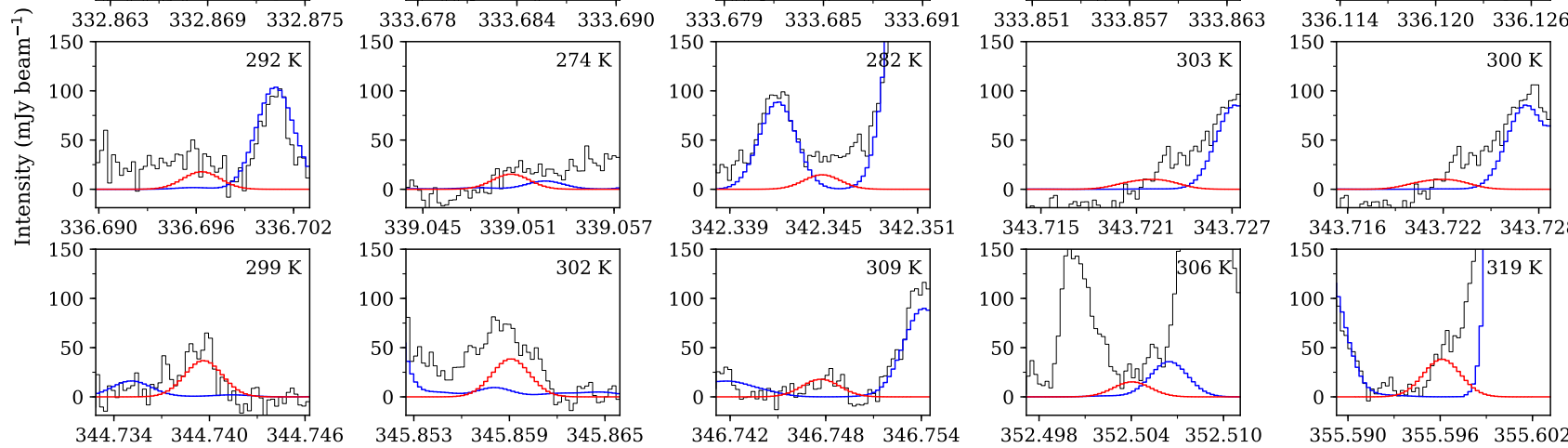

$\begin{array}{lll}343.715 & 343.721 \quad 343.727\end{array}$
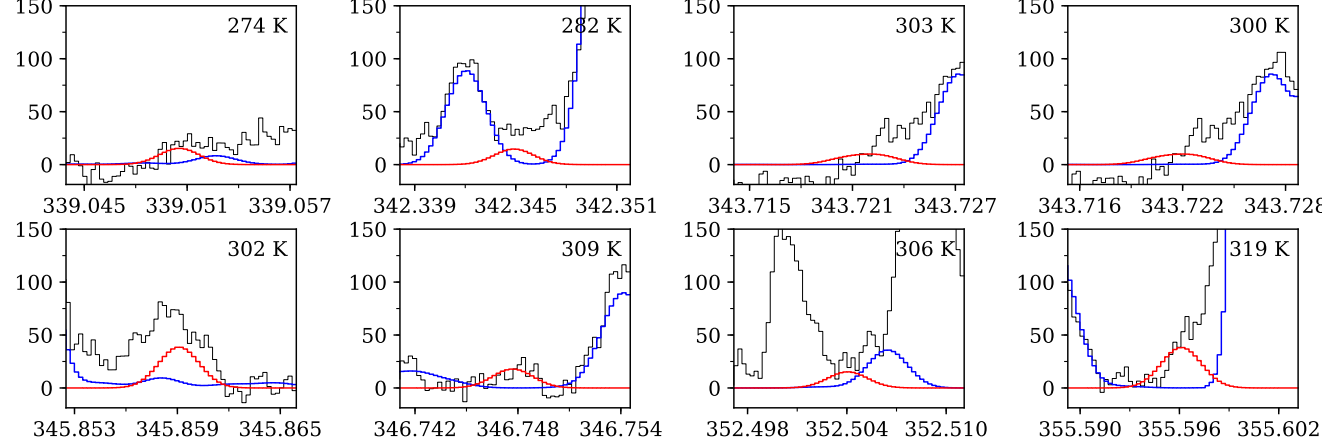

Frequency (GHz)

IRAS $16293-2422$ B
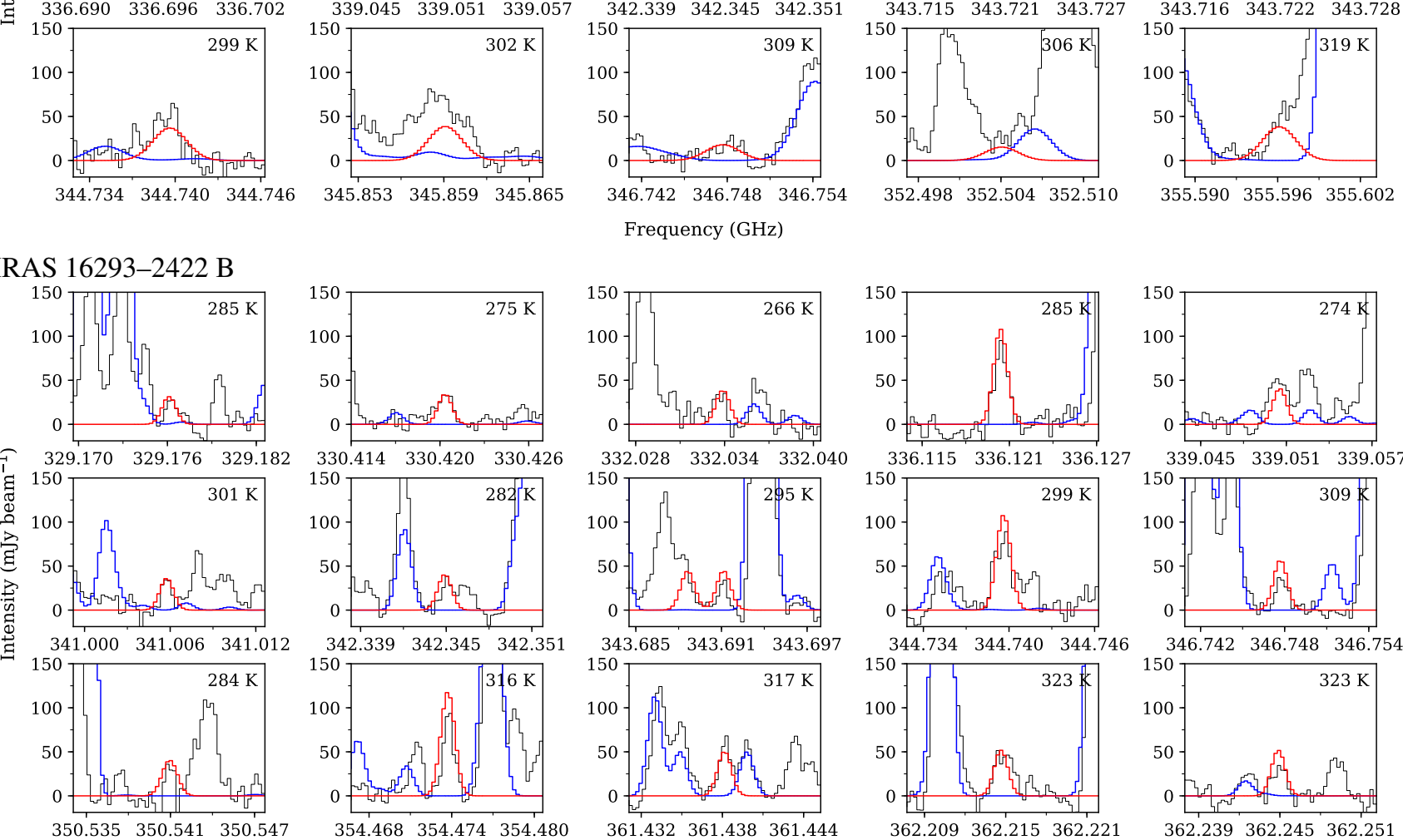

Frequency (GHz)

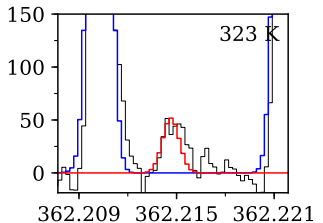

Fig. E.1. Fifteen brightest $\mathrm{CHD}_{2} \mathrm{OCHO}$ transitions towards IRAS 16293A (top panels) and IRAS 16293B (bottom panels). The synthetic spectra are over-plotted in red, a reference spectrum is shown in blue, and the data are presented in black. The upper-level energy of each transition is indicated in the top right corner of each plot. 
Table E.1 shows only the lines used in the minimisation (see Sect. 3), which correspond to only a small fraction of the total number of lines in the frequency range of the observations. There are 1963 lines for $\mathrm{CHD}_{2} \mathrm{OCHO}$ and 2137, 2226, and 134 lines for $\mathrm{CH}_{3} \mathrm{OCHO}$, $\mathrm{CH}_{2} \mathrm{DOCHO}$, and $\mathrm{CH}_{3} \mathrm{OCDO}$, respectively.

Table E.1. Line list of the observed $\mathrm{CHD}_{2} \mathrm{OCHO}$ transitions used in the fit.

\begin{tabular}{|c|c|c|c|c|}
\hline Transition $J\left(K_{\mathrm{a}}, K_{\mathrm{c}}\right)-J^{\prime}\left(K_{\mathrm{a}}^{\prime}, K_{\mathrm{c}}^{\prime}\right)$ & $v(\mathrm{GHz})$ & $g_{\mathrm{u}}$ & $E_{\mathrm{u}}(\mathrm{K})$ & $A_{\mathrm{ul}}\left(\mathrm{s}^{-1}\right)$ \\
\hline $30(5,26) \mathrm{o}^{-}-29(5,25) \mathrm{o}^{-a}$ & 332.0340 & 61 & 266 & $5.305 \times 10^{-4}$ \\
\hline $30(5,26) \mathrm{o}^{+}-29(5,25) \mathrm{o}^{+}$ & 332.0340 & 61 & 266 & $5.305 \times 10^{-4}$ \\
\hline $31(3,28) \mathrm{o}^{-}-30(3,27) \mathrm{o}^{-}$ & 333.1965 & 63 & 273 & $5.405 \times 10^{-4}$ \\
\hline $31(3,28) \mathrm{o}^{+}-30(3,27) \mathrm{o}^{+}$ & 333.1966 & 63 & 273 & $5.404 \times 10^{-4}$ \\
\hline $30(4,26) \mathrm{o}^{+}-29(4,25) \mathrm{o}^{+}$ & 333.8572 & 61 & 266 & $5.397 \times 10^{-4}$ \\
\hline $30(4,26) \mathrm{o}^{-}-29(4,25) \mathrm{o}^{-}$ & 333.8574 & 61 & 266 & $5.397 \times 10^{-4}$ \\
\hline $32(3,30) \mathrm{o}^{-}-31(3,29) \mathrm{o}^{-}$ & 333.9611 & 65 & 278 & $5.490 \times 10^{-4}$ \\
\hline $32(3,30) \mathrm{o}^{+}-31(3,29) \mathrm{o}^{+}$ & 333.9613 & 65 & 278 & $5.490 \times 10^{-4}$ \\
\hline $33(1,32) \mathrm{o}^{-}-32(2,31) \mathrm{o}^{-}$ & 335.0038 & 67 & 282 & $1.071 \times 10^{-4}$ \\
\hline $33(2,32) \mathrm{o}^{-}-32(2,31) \mathrm{o}^{-}$ & 335.0039 & 67 & 282 & $5.594 \times 10^{-4}$ \\
\hline $33(1,32) \mathrm{o}^{-}-32(1,31) \mathrm{o}^{-}$ & 335.0040 & 67 & 282 & $5.594 \times 10^{-4}$ \\
\hline $33(1,32) \mathrm{o}^{+}-32(2,31) \mathrm{o}^{+}$ & 335.0041 & 67 & 282 & $1.071 \times 10^{-4}$ \\
\hline $33(2,32) \mathrm{o}^{-}-32(1,31) \mathrm{o}^{-}$ & 335.0041 & 67 & 282 & $1.071 \times 10^{-4}$ \\
\hline $33(2,32) \mathrm{o}^{+}-32(2,31) \mathrm{o}^{+}$ & 335.0042 & 67 & 282 & $5.594 \times 10^{-4}$ \\
\hline $33(1,32) \mathrm{o}^{+}-32(1,31) \mathrm{o}^{+}$ & 335.0042 & 67 & 282 & $5.594 \times 10^{-4}$ \\
\hline $33(2,32) \mathrm{o}^{+}-32(1,31) \mathrm{o}^{+}$ & 335.0043 & 67 & 282 & $1.071 \times 10^{-4}$ \\
\hline $32(1,31) \mathrm{i}-31(2,30) \mathrm{i}$ & 335.1566 & 65 & 288 & $1.168 \times 10^{-4}$ \\
\hline $32(2,31) i-31(2,30) i$ & 335.1567 & 65 & 288 & $5.492 \times 10^{-4}$ \\
\hline $32(1,31) i-31(1,30) i$ & 335.1567 & 65 & 288 & $5.492 \times 10^{-4}$ \\
\hline $32(2,31) \mathrm{i}-31(1,30) \mathrm{i}$ & 335.1567 & 65 & 288 & $1.168 \times 10^{-4}$ \\
\hline $34(0,34) \mathrm{o}^{-}-33(1,33) \mathrm{o}^{-}$ & 336.1205 & 69 & 285 & $1.208 \times 10^{-4}$ \\
\hline $34(1,34) \mathrm{o}^{-}-33(1,33) \mathrm{o}^{-}$ & 336.1205 & 69 & 285 & $5.704 \times 10^{-4}$ \\
\hline $34(0,34) \mathrm{o}^{-}-33(0,33) \mathrm{o}^{-}$ & 336.1205 & 69 & 285 & $5.704 \times 10^{-4}$ \\
\hline $34(1,34) \mathrm{o}^{-}-33(0,33) \mathrm{o}^{-}$ & 336.1205 & 69 & 285 & $1.208 \times 10^{-4}$ \\
\hline $34(0,34) \mathrm{o}^{+}-33(1,33) \mathrm{o}^{+}$ & 336.1205 & 69 & 285 & $1.208 \times 10^{-4}$ \\
\hline $34(1,34) \mathrm{o}^{+}-33(1,33) \mathrm{o}^{+}$ & 336.1205 & 69 & 285 & $5.704 \times 10^{-4}$ \\
\hline $34(0,34) \mathrm{o}^{+}-33(0,33) \mathrm{o}^{+}$ & 336.1205 & 69 & 285 & $5.704 \times 10^{-4}$ \\
\hline $34(1,34) \mathrm{o}^{+}-33(0,33) \mathrm{o}^{+}$ & 336.1205 & 69 & 285 & $1.208 \times 10^{-4}$ \\
\hline $33(0,33) \mathrm{i}-32(1,32) \mathrm{i}$ & 336.6965 & 67 & 292 & $1.312 \times 10^{-4}$ \\
\hline $33(1,33) i-32(1,32) i$ & 336.6965 & 67 & 292 & $5.629 \times 10^{-4}$ \\
\hline $33(0,33) \mathrm{i}-32(0,32) \mathrm{i}$ & 336.6965 & 67 & 292 & $5.629 \times 10^{-4}$ \\
\hline $33(1,33) \mathrm{i}-32(0,32) \mathrm{i}$ & 336.6965 & 67 & 292 & $1.312 \times 10^{-4}$ \\
\hline $30(12,19) \mathrm{o}^{+}-29(12,18) \mathrm{o}^{+}$ & 337.9397 & 61 & 339 & $4.885 \times 10^{-4}$ \\
\hline $30(12,18) \mathrm{o}^{+}-29(12,17) \mathrm{o}^{+}$ & 337.9397 & 61 & 339 & $4.885 \times 10^{-4}$ \\
\hline $30(12,19) \mathrm{o}^{-}-29(12,18) \mathrm{o}^{-}$ & 337.9401 & 61 & 339 & $4.887 \times 10^{-4}$ \\
\hline $30(12,18) \mathrm{o}^{-}-29(12,17) \mathrm{o}^{-}$ & 337.9402 & 61 & 339 & $4.885 \times 10^{-4}$ \\
\hline $30(6,25) \mathrm{o}^{-}-29(6,24) \mathrm{o}^{-}$ & 339.0506 & 61 & 274 & $5.609 \times 10^{-4}$ \\
\hline $30(6,25) \mathrm{o}^{+}-29(6,24) \mathrm{o}^{+}$ & 339.0507 & 61 & 274 & $5.609 \times 10^{-4}$ \\
\hline $31(5,27) \mathrm{o}^{+}-30(5,26) \mathrm{o}^{+}$ & 341.8847 & 63 & 282 & $5.800 \times 10^{-4}$ \\
\hline $31(5,27) \mathrm{o}^{-}-30(5,26) \mathrm{o}^{-}$ & 341.8848 & 63 & 282 & $5.800 \times 10^{-4}$ \\
\hline $32(4,29) \mathrm{o}^{-}-31(4,28) \mathrm{o}^{-}$ & 342.7908 & 65 & 289 & $5.892 \times 10^{-4}$ \\
\hline $32(4,29) \mathrm{o}^{+}-31(4,28) \mathrm{o}^{+}$ & 342.7909 & 65 & 289 & $5.892 \times 10^{-4}$ \\
\hline $29(6,23) \mathrm{o}^{-}-28(6,22) \mathrm{o}^{-}$ & 342.8648 & 59 & 261 & $5.838 \times 10^{-4}$ \\
\hline $29(6,23) \mathrm{o}^{+}-28(6,22) \mathrm{o}^{+}$ & 342.8651 & 59 & 261 & $5.838 \times 10^{-4}$ \\
\hline $32(3,29) \mathrm{o}^{-}-31(3,28) \mathrm{o}^{-}$ & 342.8687 & 65 & 289 & $5.897 \times 10^{-4}$ \\
\hline $32(3,29) \mathrm{o}^{+}-31(3,28) \mathrm{o}^{+}$ & 342.8688 & 65 & 289 & $5.897 \times 10^{-4}$ \\
\hline $33(2,31) \mathrm{o}^{-}-32(2,30) \mathrm{o}^{-}$ & 343.6912 & 67 & 295 & $5.991 \times 10^{-4}$ \\
\hline $33(2,31) \mathrm{o}^{+}-32(2,30) \mathrm{o}^{+}$ & 343.6914 & 67 & 295 & $5.991 \times 10^{-4}$ \\
\hline $32(2,30) \mathrm{i}-31(3,29) \mathrm{i}$ & 343.7220 & 65 & 300 & $1.123 \times 10^{-4}$ \\
\hline $32(3,30) i-31(3,29) i$ & 343.7228 & 65 & 300 & $5.868 \times 10^{-4}$ \\
\hline
\end{tabular}

Notes. ${ }^{(a)}$ The $\mathrm{CHD}_{2} \mathrm{OCHO}$ torsional pattern consists of three non-degenerate sublevels, indicated by the $p$ quantum number. $\mathrm{A}$ first $10 \mathrm{~cm}^{-1}$ energy symmetry-splitting separates the $i$ and $o$ states, so-called "H-in-plane" and "H-out-plane", respectively. The lower torsional level $o$ splits again by tunneling into two sublevels, $o^{+}$and $o^{-} 10.8 \mathrm{MHz}$ above the first one (for more details, see Coudert et al. 2012). 
Table E.1. continued.

\begin{tabular}{|c|c|c|c|c|}
\hline Transition $J\left(K_{\mathrm{a}}, K_{\mathrm{c}}\right)-J^{\prime}\left(K_{\mathrm{a}}^{\prime}, K_{\mathrm{c}}^{\prime}\right)$ & $v(\mathrm{GHz})$ & $g_{\mathrm{u}}$ & $E_{\mathrm{u}}(\mathrm{K})$ & $A_{\mathrm{ul}}\left(\mathrm{s}^{-1}\right)$ \\
\hline $32(2,30) i-31(2,29) i$ & 343.7235 & 65 & 300 & $5.868 \times 10^{-4}$ \\
\hline $32(3,30) i-31(2,29) i$ & 343.7244 & 65 & 300 & $1.123 \times 10^{-4}$ \\
\hline $34(1,33) \mathrm{o}^{-}-33(2,32) \mathrm{o}^{-}$ & 344.7396 & 69 & 299 & $1.173 \times 10^{-4}$ \\
\hline $34(2,33) \mathrm{o}^{-}-33(2,32) \mathrm{o}^{-}$ & 344.7396 & 69 & 299 & $6.101 \times 10^{-4}$ \\
\hline $34(1,33) \mathrm{o}^{-}-33(1,32) \mathrm{o}^{-}$ & 344.7396 & 69 & 299 & $6.101 \times 10^{-4}$ \\
\hline $34(2,33) \mathrm{o}^{-}-33(1,32) \mathrm{o}^{-}$ & 344.7397 & 69 & 299 & $1.173 \times 10^{-4}$ \\
\hline $34(1,33) \mathrm{o}^{+}-33(2,32) \mathrm{o}^{+}$ & 344.7398 & 69 & 299 & $1.173 \times 10^{-4}$ \\
\hline $34(2,33) \mathrm{o}^{+}-33(2,32) \mathrm{o}^{+}$ & 344.7398 & 69 & 299 & $6.101 \times 10^{-4}$ \\
\hline $34(1,33) \mathrm{o}^{+}-33(1,32) \mathrm{o}^{+}$ & 344.7399 & 69 & 299 & $6.101 \times 10^{-4}$ \\
\hline $34(2,33) \mathrm{o}^{+}-33(1,32) \mathrm{o}^{+}$ & 344.7399 & 69 & 299 & $1.173 \times 10^{-4}$ \\
\hline $33(1,32) \mathrm{i}-32(2,31) \mathrm{i}$ & 345.2040 & 67 & 305 & $1.283 \times 10^{-4}$ \\
\hline $33(2,32) \mathrm{i}-32(2,31) \mathrm{i}$ & 345.2040 & 67 & 305 & $6.006 \times 10^{-4}$ \\
\hline $33(1,32) i-32(1,31) i$ & 345.2040 & 67 & 305 & $6.006 \times 10^{-4}$ \\
\hline $33(2,32) \mathrm{i}-32(1,31) \mathrm{i}$ & 345.2041 & 67 & 305 & $1.283 \times 10^{-4}$ \\
\hline $35(0,35) \mathrm{o}^{-}-34(1,34) \mathrm{o}^{-}$ & 345.8592 & 71 & 302 & $1.318 \times 10^{-4}$ \\
\hline $35(1,35) \mathrm{o}^{-}-34(1,34) \mathrm{o}^{-}$ & 345.8592 & 71 & 302 & $6.218 \times 10^{-4}$ \\
\hline $35(0,35) \mathrm{o}^{-}-34(0,34) \mathrm{o}^{-}$ & 345.8592 & 71 & 302 & $6.218 \times 10^{-4}$ \\
\hline $35(1,35) \mathrm{o}^{-}-34(0,34) \mathrm{o}^{-}$ & 345.8592 & 71 & 302 & $1.318 \times 10^{-4}$ \\
\hline $35(0,35) \mathrm{o}^{+}-34(1,34) \mathrm{o}^{+}$ & 345.8592 & 71 & 302 & $1.318 \times 10^{-4}$ \\
\hline $35(1,35) \mathrm{o}^{+}-34(1,34) \mathrm{o}^{+}$ & 345.8592 & 71 & 302 & $6.218 \times 10^{-4}$ \\
\hline $35(0,35) \mathrm{o}^{+}-34(0,34) \mathrm{o}^{+}$ & 345.8592 & 71 & 302 & $6.218 \times 10^{-4}$ \\
\hline $35(1,35) \mathrm{o}^{+}-34(0,34) \mathrm{o}^{+}$ & 345.8592 & 71 & 302 & $1.318 \times 10^{-4}$ \\
\hline $34(0,34) \mathrm{i}-33(1,33) \mathrm{i}$ & 346.7478 & 69 & 309 & $1.435 \times 10^{-4}$ \\
\hline $34(1,34) \mathrm{i}-33(1,33) \mathrm{i}$ & 346.7478 & 69 & 309 & $6.151 \times 10^{-4}$ \\
\hline $34(0,34) \mathrm{i}-33(0,33) \mathrm{i}$ & 346.7478 & 69 & 309 & $6.151 \times 10^{-4}$ \\
\hline $34(1,34) \mathrm{i}-33(0,33) \mathrm{i}$ & 346.7478 & 69 & 309 & $1.435 \times 10^{-4}$ \\
\hline $31(12,20) \mathrm{o}^{+}-30(12,19) \mathrm{o}^{+}$ & 349.4138 & 63 & 356 & $5.468 \times 10^{-4}$ \\
\hline $31(12,19) \mathrm{o}^{+}-30(12,18) \mathrm{o}^{+}$ & 349.4139 & 63 & 356 & $5.468 \times 10^{-4}$ \\
\hline $31(12,20) \mathrm{o}^{-}-30(12,19) \mathrm{o}^{-}$ & 349.4142 & 63 & 356 & $5.468 \times 10^{-4}$ \\
\hline $31(12,19) \mathrm{o}^{-}-30(12,18) \mathrm{o}^{-}$ & 349.4143 & 63 & 356 & $5.468 \times 10^{-4}$ \\
\hline $32(4,28) \mathrm{o}^{+}-31(4,27) \mathrm{o}^{+}$ & 352.5493 & 65 & 299 & $6.371 \times 10^{-4}$ \\
\hline $32(4,28) \mathrm{o}^{-}-31(4,27) \mathrm{o}^{-}$ & 352.5495 & 65 & 299 & $6.371 \times 10^{-4}$ \\
\hline $34(3,32) \mathrm{o}^{-}-33(3,31) \mathrm{o}^{-}$ & 353.4151 & 69 & 312 & $6.520 \times 10^{-4}$ \\
\hline $34(3,32) \mathrm{o}^{+}-33(3,31) \mathrm{o}^{+}$ & 353.4153 & 69 & 312 & $6.520 \times 10^{-4}$ \\
\hline $35(1,34) \mathrm{o}^{-}-34(2,33) \mathrm{o}^{-}$ & 354.4737 & 71 & 316 & $1.282 \times 10^{-4}$ \\
\hline $35(2,34) \mathrm{o}^{-}-34(2,33) \mathrm{o}^{-}$ & 354.4737 & 71 & 316 & $6.638 \times 10^{-4}$ \\
\hline $35(1,34) \mathrm{o}^{-}-34(1,33) \mathrm{o}^{-}$ & 354.4737 & 71 & 316 & $6.638 \times 10^{-4}$ \\
\hline $35(2,34) \mathrm{o}^{-}-34(1,33) \mathrm{o}^{-}$ & 354.4738 & 71 & 316 & $1.282 \times 10^{-4}$ \\
\hline $35(1,34) \mathrm{o}^{+}-34(2,33) \mathrm{o}^{+}$ & 354.4739 & 71 & 316 & $1.282 \times 10^{-4}$ \\
\hline $35(2,34) \mathrm{o}^{+}-34(2,33) \mathrm{o}^{+}$ & 354.4740 & 71 & 316 & $6.637 \times 10^{-4}$ \\
\hline $35(1,34) \mathrm{o}^{+}-34(1,33) \mathrm{o}^{+}$ & 354.4740 & 71 & 316 & $6.637 \times 10^{-4}$ \\
\hline $35(2,34) \mathrm{o}^{+}-34(1,33) \mathrm{o}^{+}$ & 354.4740 & 71 & 316 & $1.282 \times 10^{-4}$ \\
\hline $30(6,24) \mathrm{o}^{-}-29(6,23) \mathrm{o}^{-}$ & 354.6897 & 61 & 278 & $6.481 \times 10^{-4}$ \\
\hline $30(6,24) \mathrm{o}^{+}-29(6,23) \mathrm{o}^{+}$ & 354.6898 & 61 & 278 & $6.481 \times 10^{-4}$ \\
\hline $34(1,33) \mathrm{i}-33(2,32) \mathrm{i}$ & 355.2495 & 69 & 322 & $1.405 \times 10^{-4}$ \\
\hline $34(2,33) \mathrm{i}-33(2,32) \mathrm{i}$ & 355.2495 & 69 & 322 & $6.552 \times 10^{-4}$ \\
\hline $34(1,33) \mathrm{i}-33(1,32) \mathrm{i}$ & 355.2495 & 69 & 322 & $6.552 \times 10^{-4}$ \\
\hline $34(2,33) \mathrm{i}-33(1,32) \mathrm{i}$ & 355.2495 & 69 & 322 & $1.405 \times 10^{-4}$ \\
\hline $36(0,36) \mathrm{o}^{-}-35(1,35) \mathrm{o}^{-}$ & 355.5962 & 73 & 319 & $1.435 \times 10^{-4}$ \\
\hline $36(1,36) \mathrm{o}^{-}-35(1,35) \mathrm{o}^{-}$ & 355.5962 & 73 & 319 & $6.761 \times 10^{-4}$ \\
\hline $36(0,36) \mathrm{o}^{-}-35(0,35) \mathrm{o}^{-}$ & 355.5962 & 73 & 319 & $6.761 \times 10^{-4}$ \\
\hline $36(1,36) \mathrm{o}^{-}-35(0,35) \mathrm{o}^{-}$ & 355.5962 & 73 & 319 & $1.435 \times 10^{-4}$ \\
\hline $36(0,36) \mathrm{o}^{+}-35(1,35) \mathrm{o}^{+}$ & 355.5963 & 73 & 319 & $1.436 \times 10^{-4}$ \\
\hline $36(1,36) \mathrm{o}^{+}-35(1,35) \mathrm{o}^{+}$ & 355.5963 & 73 & 319 & $6.761 \times 10^{-4}$ \\
\hline $36(0,36) \mathrm{o}^{+}-35(0,35) \mathrm{o}^{+}$ & 355.5963 & 73 & 319 & $6.761 \times 10^{-4}$ \\
\hline $36(1,36) \mathrm{o}^{+}-35(0,35) \mathrm{o}^{+}$ & 355.5963 & 73 & 319 & $1.436 \times 10^{-4}$ \\
\hline $32(12,21) \mathrm{o}^{+}-31(12,20) \mathrm{o}^{+}$ & 360.9101 & 65 & 373 & $6.096 \times 10^{-4}$ \\
\hline $32(12,20) \mathrm{o}^{+}-31(12,19) \mathrm{o}^{+}$ & 360.9104 & 65 & 373 & $6.096 \times 10^{-4}$ \\
\hline $32(12,21) \mathrm{o}^{-}-31(12,20) \mathrm{o}^{-}$ & 360.9104 & 65 & 373 & $6.096 \times 10^{-4}$ \\
\hline
\end{tabular}


A\&A 623, A69 (2019)

Table E.1. continued.

\begin{tabular}{ccccc}
\hline \hline Transition $J\left(K_{\mathrm{a}}, K_{\mathrm{c}}\right)-J^{\prime}\left(K_{\mathrm{a}}^{\prime}, K_{\mathrm{c}}^{\prime}\right)$ & $v(\mathrm{GHz})$ & $g_{\mathrm{u}}$ & $E_{\mathrm{u}}(\mathrm{K})$ & $A_{\mathrm{ul}}\left(\mathrm{s}^{-1}\right)$ \\
\hline $32(12,20) \mathrm{o}^{-}-31(12,19) \mathrm{o}^{-}$ & 360.9107 & 65 & 373 & $6.096 \times 10^{-4}$ \\
$33(5,29) \mathrm{o}^{+}-32(5,28) \mathrm{o}^{+}$ & 361.4382 & 67 & 317 & $6.872 \times 10^{-4}$ \\
$33(5,29) \mathrm{o}^{-}-32(5,28) \mathrm{o}^{-}$ & 361.4383 & 67 & 317 & $6.872 \times 10^{-4}$ \\
$34(4,31) \mathrm{o}^{-}-33(4,30) \mathrm{o}^{-}$ & 362.2148 & 69 & 323 & $6.968 \times 10^{-4}$ \\
$34(4,31) \mathrm{o}^{+}-33(4,30) \mathrm{o}^{+}$ & 362.2148 & 69 & 323 & $6.968 \times 10^{-4}$ \\
$34(3,31) \mathrm{o}^{-}-33(3,30) \mathrm{o}^{-}$ & 362.2450 & 69 & 323 & $6.971 \times 10^{-4}$ \\
$34(3,31) \mathrm{o}^{+}-33(3,30) \mathrm{o}^{+}$ & 362.2450 & 69 & 323 & $6.971 \times 10^{-4}$ \\
\hline
\end{tabular}

